\title{
Device Engineering for All-Inorganic Perovskite Light-Emitting Diodes
}

\author{
Dongxiang Luo ${ }^{1}$, Qizan Chen ${ }^{1}$, Ying Qiu ${ }^{2, *}$, Menglong Zhang ${ }^{1,3}$ and Baiquan Liu ${ }^{4,5, *}$ \\ 1 School of Materials and Energy, Guangdong University of Technology, Guangzhou 510006, China \\ 2 Guangdong R\&D Center for Technological Economy, Guangzhou 510000, China \\ 3 Institute of Semiconductors, South China Normal University, Guangzhou 510000, China \\ 4 State Key Laboratory of Luminescent Materials and Devices, South China University of Technology, \\ Guangzhou 510640, China \\ 5 LUMINOUS! Centre of Excellent for Semiconductor Lighting and Displays, School of Electrical and \\ Electronic Engineering, Nanyang Technological University, Nanyang Avenue, Singapore 639798, Singapore \\ * Correspondence: srawoyjs@sina.com (Y.Q.); 1.baiquan@mail.scut.edu.cn (B.L.)
}

Received: 10 June 2019; Accepted: 10 July 2019; Published: 12 July 2019

check for updates

\begin{abstract}
Recently, all-inorganic perovskite light-emitting diodes (PeLEDs) have attracted both academic and industrial interest thanks to their outstanding properties, such as high efficiency, bright luminance, excellent color purity, low cost and potentially good operational stability. Apart from the design and treatment of all-inorganic emitters, the device engineering is another significant factor to guarantee the high performance. In this review, we have summarized the state-of-the-art concepts for device engineering in all-inorganic PeLEDs, where the charge injection, transport, balance and leakage play a critical role in the performance. First, we have described the fundamental concepts of all-inorganic PeLEDs. Then, we have introduced the enhancement of device engineering in all-inorganic PeLEDs. Particularly, we have comprehensively highlighted the emergence of all-inorganic PeLEDs, strategies to improve the hole injection, approaches to enhance the electron injection, schemes to increase the charge balance and methods to decrease the charge leakage. Finally, we have clarified the issues and ways to further enhance the performance of all-inorganic PeLEDs.
\end{abstract}

Keywords: light-emitting diode; all-inorganic perovskite; charge injection; charge balance; charge leakage

\section{Introduction}

In the recent years, halide perovskites have emerged as a novel class of optoelectronic materials for many fields (e.g., solar cells, lasers and photodetectors) due to their excellent properties including size-tunable optical bandgaps, narrow emission and excellent charge-transport capabilities [1-6]. In particular, the property of size-tunable optical bandgaps in perovskites is the same as that of conventional metal chalcogenide semiconductors [7]. For example, Protesescu et al. demonstrated size-dependent photoluminescence (PL) emission from $\mathrm{CsPbBr}_{3}$ nanocrystals, where the PL peak shifted from 512 to $460 \mathrm{~nm}$ with the edge size decreasing from 11.8 to $3.8 \mathrm{~nm}$ [8]. Additionally, the perovskite sizes can be controlled by reaction temperatures to tune the bandgap (e.g., the size decreases by decreasing the reaction temperature) [9]. Such outstanding characteristics also render that halide perovskites can be used as the emitters for light-emitting diodes (LEDs) [10-15]. In 2014, Tan et al. reported the first hybrid organic-inorganic $\mathrm{CH}_{3} \mathrm{NH}_{3} \mathrm{PbBr}_{3}$ perovskite LED (PeLED) [16]. Although the external quantum efficiency (EQE) of their green device is only $0.1 \%$, this groundbreaking finding unlocks a new door for the application of perovskites in LEDs. Since then, PeLEDs have rapidly attracted a great deal of attention from both academic and industrial researchers. To date, some groups have realized PeLEDs with EQE exceeding 20\% [17,18]. 
In 2015, Zeng et al. demonstrated all-inorganic PeLEDs, where $\mathrm{CsPb}(\mathrm{Cl} / \mathrm{Br})_{3}, \mathrm{CsPbBr}_{3}$ and $\mathrm{CsPb}(\mathrm{Br} / \mathrm{I})_{3}$ were used as the blue, green and orange emitter, respectively [19]. This finding showed that all-inorganic perovskites could be a new class of emitters in LEDs, despite the EQE of the devices is low (e.g., an EQE of $0.12 \%$ for the green all-inorganic PeLEDs). Compared with hybrid organic-inorganic perovskite materials, all-inorganic perovskites (e.g., $\mathrm{CsPbX}_{3}, \mathrm{X}=\mathrm{I}, \mathrm{Br}$ and $\mathrm{Cl}$ or mixed halide systems $\mathrm{Br} / \mathrm{I}$ and $\mathrm{Cl} / \mathrm{Br}$ ) have better thermal stability [20-22], which is more beneficial to the practical use. In addition, all-inorganic perovskites could possess excellent PL quantum yield (PLQY, e.g., near unity in solution), ensuring the development of highly efficient all-inorganic PeLEDs [23-26]. Furthermore, all-inorganic perovskites can show exceptional color purity (e.g., full width at half-maximum (FWHM) $<20 \mathrm{~nm}$ ) and be compatible with the solution-processable technique, triggering intense interest in applying them for PeLEDs [27-30]. Therefore, since the first report of all-inorganic PeLED [19], the performances of all-inorganic PeLEDs (e.g., EQE, current efficiency, power efficiency, luminance or brightness, lifetime and voltage) have been greatly enhanced over the past five years [31-35]. Currently, the highest EQE of all-inorganic PeLEDs is above 20\% [36], which is comparable to the state-of-the-art organic LEDs (OLEDs) [37-41] and CdSe-based quantum-dot LEDs (QD-LEDs) [42-46]. As a matter of fact, a large number of high-efficiency all-inorganic perovskite LEDs have been reported. Before achieving the record EQE of $21.3 \%$ for red devices [36], Kido's group reported highly efficient green all-inorganic perovskite LEDs. For example, an EQE of $8.73 \%$ was obtained via effective washing process and interfacial energy level alignment, which was the best efficiency in 2017 [47]. They also obtained a green all-inorganic perovskite LED with an EQE of $8.08 \%$ by exploiting low-dielectric-constant washing solvent "diglyme" [48]. After the first report of all-inorganic PeLEDs, Zeng's group proposed a series of strategies to improve the device performance. By controlling the ligand density, they achieved a green PeLEDs with an EQE of $6.27 \%$ [49]. Later, an EQE of $11.7 \%$ was attained through room-temperature triple-ligand surface engineering [50] and an EQE of $16.48 \%$ was yielded via organic-inorganic hybrid passivation [51]. For red all-inorganic PeLEDs, Yu's group designed a plenty of methods to increase the efficiency. An EQE of $6.3 \%$ was reported by enhancing the electron injection [52], an EQE of $11.8 \%$ was realized with the utilization of $\mathrm{PbS}$ capped $\mathrm{CsPbI}_{3}$ emitter [53] and an EQE of 8.2\% was achieved for flexible red devices [54]. In the case of blue all-inorganic PeLEDs, the record EQE is 1.9\% [55]. Thus, the all-inorganic PeLED technology is believed to be promising for the future-generation displays and lighting [56-60].

To develop high-performance all-inorganic PeLEDs, one crucial way is the optimization of emitting materials $\mathrm{CsPbX}_{3}$ [61-66]. In fact, most of the reports about all-inorganic PeLEDs are mainly focused on this way. For the further development of all-inorganic PeLEDs, the innovation of device engineering is essential and may be more critical [67-71]. For example, Rogach et al. sandwiched a thin film of perfluorinated ionomer (PFI) between the perovskite emissive layer (EML) and hole transport layer (HTL) to improve the hole injection, resulting in three times enhancement for the peak luminance of $\mathrm{CsPBBr}_{3}$ PeLEDs [72]. To improve the device engineering, one scheme is to explore the unique characteristic of all-inorganic PeLEDs. In addition, by drawing on the reported concepts in OLEDs, CdSe-based QD-LEDs and other related optoelectronic technologies [73-77], high-performance all-inorganic PeLEDs can be expected via the enhancement of device engineering.

Herein, the state-of-the-art concepts for device engineering in all-inorganic PeLEDs will be summarized, where the charge injection, transport, balance and leakage have a great influence on the performance. First, the fundamental concepts of all-inorganic PeLEDs will be described. Then, the enhancement of device engineering in all-inorganic PeLEDs will be introduced. At last, the issues and ways to further enhance the performance of all-inorganic PeLEDs will be briefly clarified. 


\section{Fundamental Concepts of All-Inorganic PeLEDs}

\subsection{All-Inorganic Perovskite Emitters}

$\mathrm{CsPbX}_{3}$ is isostructural to perovskite $\mathrm{CaTiO}_{3}$ and related oxides, which has been studied for more than 60 years [78]. In 2015, Kovalenko et al. for the first time reported the successful form of colloidal $\mathrm{CsPbX}_{3}$ nanocrystal QDs (4-15 nm edge lengths), which showed visible spectral region of 410-700 nm, narrow PL emission FWHM of 12-42 nm, wide color gamut, high PLQYs of up to 90\%, and short radiative lifetimes in the range of 1-29 ns [8]. Figure 1 depicts the typical monodisperse $\mathrm{CsPbX}_{3}$ nanocrystal QDs synthesized via the hot-injection method and their structural characterization. However, it is noted that the hot-injection method may exhibit some shortcomings (e.g., high temperature, inert atmosphere and high localization of injected agents exist in the hot-injection procedures). To loosen this bottleneck, Zeng et al. in 2016 reported a facile and high-yield fabrication of stable $\mathrm{CsPbX}_{3}$ QDs with high optical merits, where the PLQY could be up to $95 \%$ via supersaturated recrystallization at room temperature, free from inert-gas protection and injection operation [79]. For $\mathrm{CsPbX}_{3}$ nanocrystals, their optical characteristics can be tuned by adjusting the composition of halide ions, varying the degree of the cations, and controlling the size of perovskite nanocrystals because of the quantum confinement effect [80]. With such tunable properties, $\mathrm{CsPbX}_{3}$ nanocrystals have vast potential to be one of the excellent emitters [81-85]. In PeLEDs, the ligand density of $\mathrm{CsPbX}_{3}$ nanocrystals has an important influence on the performance. This is because ligands have double-side effect: (i) Enough ligands can give surface passivation to eliminate surface defects, ensuring high PLQY and ink stability; (ii) excessive ligands form insulating layers as oleylamine and oleic acid organics show weak electric conductivity, preventing the charge injection [86-92]. Therefore, how to achieve the trade-off between surface passivation and charge injection via ligands control is key to all-inorganic PeLEDs.


Figure 1. Monodisperse $\mathrm{CsPbX}_{3}$ nanocrystals. (a) Schematic of the cubic perovskite lattice; $(\mathbf{b}, \mathbf{c})$ transmission electron microscopy (TEM) images of $\mathrm{CsPbBr}_{3}$ nanocrystals; (d) X-ray diffraction patterns for typical ternary and mixed-halide nanocrystals. Reproduced from Reference [8].

Aside from the colloidal nanocrystals, $\mathrm{CsPbX}_{3}$ thin films, which are achieved by spin-coating or vacuum-evaporating the precursors, can be functioned the emitters of all-inorganic PeLEDs. In 2005, Yantara et al. reported the first all-inorganic PeLED based on $\mathrm{CsPbBr}_{3}$ thin films through controlled modulation of the trap density by varying the $\mathrm{CsBr}-\mathrm{PbBr}_{2}$ precursor concentration, achieving a maximum luminance of $407 \mathrm{~cd} \mathrm{~m}^{-2}$ [93]. In the case of vacuum-evaporating $\mathrm{CsPbX}_{3}$ thin films, Liao et al. demonstrated efficient all-inorganic PeLEDs in 2017 via co-evaporation of CsBr and $\mathrm{PbBr}_{2}$ based on a vacuum thermal evaporation process, yielding a maximum EQE of 1.55\% [94]. Thus, 
the various strategies of forming $\mathrm{CsPbX}_{3}$ emitters have inspired remarkable interest in the investigation of electrically driven devices [95-99].

\subsection{Device Architectures}

Similar to OLEDs and CdSe-based QD-LEDs, all-inorganic PeLEDs can be realized via the normal or inverted architectures [100-104], as shown in Figure 2. For the electroluminescent processes, holes and electrons will be first injected from anode and cathode, respectively. Then, by virtue of the hole injection layer (HIL) and HTL, holes will reach the EML. On the other hand, electrons will arrive at the EML via the electron injection layer (EIL) and electron transport layer (ETL). With the insertion of all-inorganic perovskite emitters between HTL and ETL, holes and electrons will meet each other to form excitons for radiative recombination. As a result, emissions will be generated [105-109]. Due to the almost similar device architectures, many concepts in OLEDs and CdSe-based QD-LEDs can be applied into all-inorganic PeLEDs. This may be also the reason for the fact that the EQE of all-inorganic PeLEDs can quickly overtake $20 \%$ in about five years.

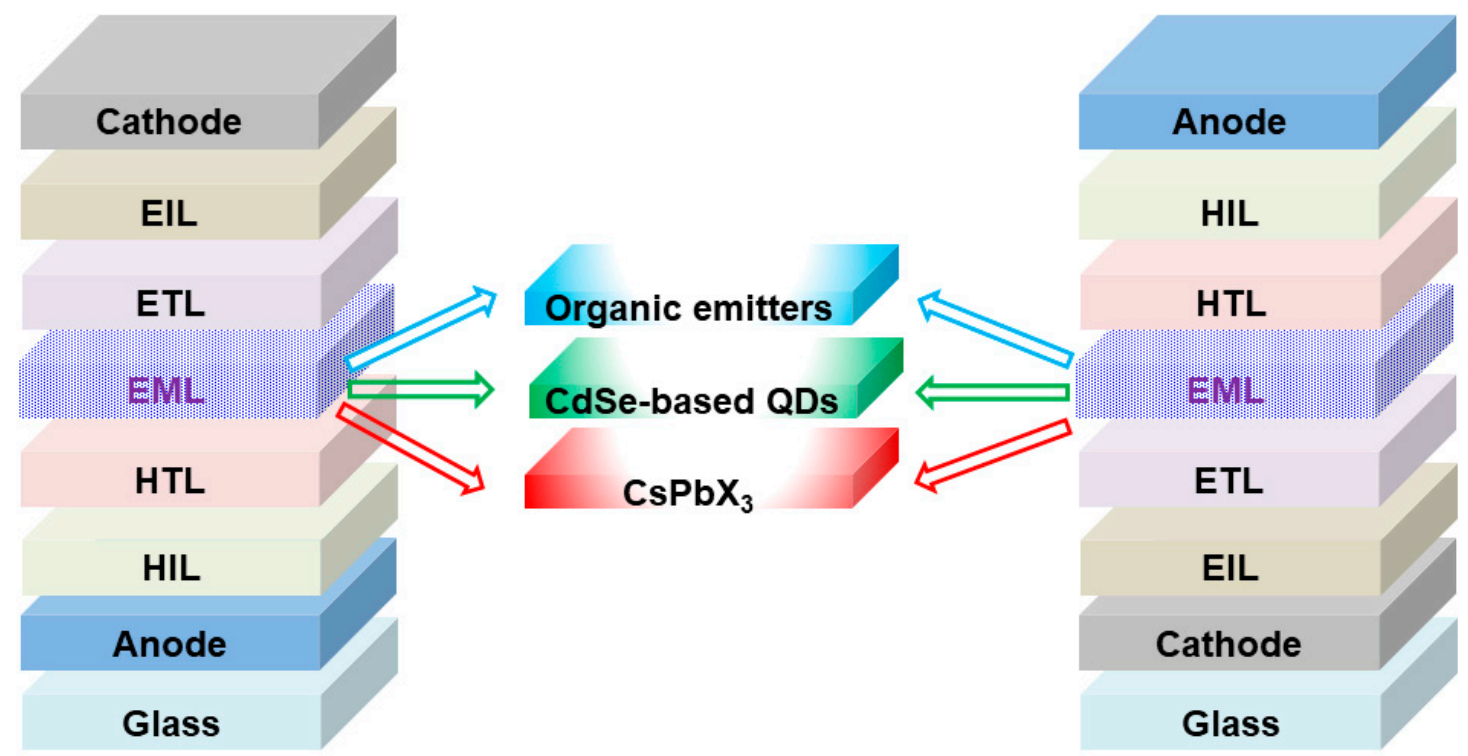

Figure 2. The diagram of device architectures of LEDs with various emitters, i.e., organic emitters for organic LEDs (OLEDs), CdSe-based quantum dots (QDs) and $\mathrm{CsPbX}_{3}$ for all-inorganic perovskite LEDs (PeLEDs). Left: The normal structures. Right: The inverted structures.

Although both normal and inverted device architectures can be utilized to build all-inorganic PeLEDs, high-performance devices are generally constructed by the normal architectures. As a matter of fact, most of all-inorganic PeLEDs are reported with normal architectures [110-115]. One of the reasons is that the energy levels of all-inorganic perovskite are well matched with neighboring charge transport layers, which ensures enough charges can be reached the EML. For example, the valence band maximum (VBM) of $\mathrm{CsPbBr}_{3}$ is $5.9 \mathrm{eV}$ [116], matching the highest occupied molecular orbital (HOMO) of typical HTLs, including poly-( $N$-vinylcarbazole) (PVK, $5.6 \mathrm{eV})$ and poly $\left(N, N^{\prime}\right.$-bis(4-butylphenyl- $N, N^{\prime}$-bis(phenyl) benzidine) (poly-TPD, $5.4 \mathrm{eV}$ ) [116]. On the other hand, the conduction band minimum (CBM) of $\mathrm{CsPbBr}_{3}$ is $3.6 \mathrm{eV}$ [105], which is much lower than the lowest unoccupied molecular orbital (LUMO) of representative 1,3,5-tris(Nphenyl-benzimidazol-2-yl)benzene (TPBi, $2.7 \mathrm{eV}$ ) ETL [117], indicating that the electrons are barrier-free when they are transported from the ETL to the EML [118-122]. Therefore, both holes and electrons can be readily transported within the normal architectures. However, it is deserved to point out that the ETL, EIL and cathode of all-inorganic PeLEDs with normal architectures are usually deposited by the vacuum-evaporated technology instead of solution-processed technique. The negligible attention was paid on all-solution-processed devices 
may be attributed to the fact the penetration effect between ETL and perovskites is still challenging to resolve, although the all-solution-processed technique exhibits more merits (e.g., lower cost, simpler fabrication and less time) [123-127].

For the inverted architectures, the most widely used EIL or ETL is zinc oxide ( $\mathrm{ZnO})$ due to its high electron mobility $\left(\sim 1.3 \times 10^{-3} \mathrm{~cm}^{2} \mathrm{~V}^{-1} \mathrm{~s}^{-1}\right)$ [87]. However, there is an electron barrier between the $\mathrm{CBM}$ of $\mathrm{ZnO}(4.4 \mathrm{eV})$ and $\mathrm{CsPbBr}_{3}(3.6 \mathrm{eV})$, although the electron barrier between the $\mathrm{CBM}$ of $\mathrm{ZnO}$ and the work function of indium tin oxide (ITO, $\sim 4.7 \mathrm{eV}$ ) is small [128-130]. Hence, it is not easy for the electron injection in inverted all-inorganic PeLEDs. By adopting more efficient ETLs, modifying the typical ZnO ETL, or inserting an interlayer between the ETL and EML to reduce the interfacial barrier [131-135], high-performance devices may be expected. Considering the fact that the most efficient PeLEDs were realized by using normal device architectures $[17,18]$, there is much room for the further investigation of inverted architecture.

\section{The Device Engineering in All-Inorganic PeLEDs}

\subsection{Basic Aspects of Device Engineering}

According to the above concepts, aside from the consideration of perovskite emitters, the innovation of device engineering is another element to determine the performance of all-inorganic PeLEDs. After the selection of perovskites, the EQE is vitally affected by the charge balance from the perspective of device engineering [136-145]. This is because the EQE in LEDs is defined as follows [146-150]:

$$
\mathrm{EQE}=\eta_{\text {out }} \cdot r \cdot q \cdot \gamma
$$

where $\eta_{\text {out }}$ represents the outcoupling factor, $r$ represents the fraction of excitons that potentially radiatively decay, $q$ represents the PLQY and $\gamma$ represents the charge balance. In general, $\eta_{\text {out }}$ is not influenced by the internal operation of LEDs, while $r$ and $q$ are fixed by emitters. Thus, $\gamma$ plays a significant role in the device efficiency. In fact, how to manage the charge injection, transport, balance and leakage are key to achieve satisfactory performances, i.e., high efficiency, bright luminance and long lifetime [151-155]. In addition, the power efficiency is inversely proportional to the operational voltage [156-160]. Hence, the low voltage is essential to produce high power efficiency.

To enhance the device engineering, enough holes and electrons are required to meet at the perovskite EMLs, forming excitons (i.e., excited electron-hole pairs [96]) for emissions. Generally, the large exciton binding energy and the short exciton diffusion length are required to enhance the efficiency of PeLEDs [161]. Thus, the charge injection and transport should be very effectively manipulated [162-164]. In addition, the number of holes is ideal to be equal to that of electrons, guaranteeing the charge balance [165-167]. Moreover, to reduce the charge leakage, uniform EML films and charge blocking layers are desirable [168-173]. As a matter of fact, some innovations of device engineering in all-inorganic PeLEDs were reported based on these concepts, which will be introduced in the following sections.

\subsection{Emergence of All-Inorganic PeLEDs}

At the initial stage for the development of halide perovskite optoelectronic devices, most of the attentions were paid on solar cells. With the step-by-step discovery of amazing characteristics of perovskite materials, researchers are motivated to fabricate hybrid organic-inorganic PeLEDs. To solve the stability issue of organic-inorganic perovskites, all-inorganic PeLEDs are developed [174-178]. In 2015, Zeng et al. took the first step to construct all-inorganic PeLEDs, where the emitters $\mathrm{CsPbX}_{3}$ $(\mathrm{X}=\mathrm{Cl}, \mathrm{Br}, \mathrm{I}) \mathrm{QDs}$ were synthesized through hot-injecting cesium stearate (CsSt) to $\mathrm{PbBr}_{2}$ solution [19]. As shown in Figure 3, the device architecture was ITO/poly(ethylenedioxythiophene):polystyrene sulfonate (PEDOT:PSS, $40 \mathrm{~nm})$, PVK $(10 \mathrm{~nm}) /$ perovskite QDs $(10 \mathrm{~nm}) / \mathrm{TPBi}(40 \mathrm{~nm}) / \mathrm{LiF}(1 \mathrm{~nm}) / \mathrm{Al}$ $(100 \mathrm{~nm})$, in which QDs were $\mathrm{CsPb}(\mathrm{Cl} / \mathrm{Br})_{3}, \mathrm{CsPbBr}_{3}$ and $\mathrm{CsPb}(\mathrm{Br} / \mathrm{I})_{3}$ for blue, green and orange electroluminescence, respectively. For the blue, green, and orange PeLEDs, luminances of 742, 946 and 
$528 \mathrm{~cd} \mathrm{~m}^{-2}$, with EQEs of $0.07 \%, 0.12 \%$ and $0.09 \%$ were achieved, respectively. In their device architecture, TPBi was employed as ETL, while PVK was used as HTL and electron blocking layers. PVK could reduce the hole injection barrier, block the electron in the active layer, and hence allow holes and electrons to recombine in EMLs. As a result, no any notable parasitic emissions originated from the charge transport layer could be observed in the entire electroluminescence spectrum under varied voltages. In fact, such device architecture is very effective and becomes one of the most popular architectures. For example, the most efficient blue all-inorganic PeLED was fabricated via this architecture, yielding the EQE of $1.9 \%$ [55].


Figure 3. Illustration of PeLEDs. (a) The device structure. (b) Cross-sectional TEM image showing the multiple layers. Scale bar, $50 \mathrm{~nm}$. (c) Flat-band energy level diagram. Reproduced from reference [19], with permission from John Wiley and Sons, 2015.

At the almost same time, Yantara et al. reported all-inorganic PeLEDs by using $\mathrm{CsPbBr}_{3}$ thin films as the emitter [93]. As shown in Figure 4, the device architecture was ITO/PEDOT:PSS/CsPbBr $3 /$ poly(9,9-di-n-octylfluorenyl-2,7-diyl) (F8)/Ca $(20 \mathrm{~nm}) / \mathrm{Al}(80 \mathrm{~nm})$, in which the trap density of low temperature $\left(70{ }^{\circ} \mathrm{C}\right)$ solution-processed $\mathrm{CsPbBr}_{3}$ was reduced by varying their precursor concentration (i.e., using $\mathrm{CsBr}$-rich solution). For varied $\mathrm{CsBr} / \mathrm{PbBr}_{2}$ ratio (i.e., 0.8, 1.0, 2.0 and 3.0), the outcome of the reactions in DMSO solvent was different. Clear solutions were obtained from $\mathrm{CsBr} / \mathrm{PbBr}_{2}$ ratio $\leq 1.0$ (after stirring for $5 \mathrm{~h}$ in room temperature), while precipitates were observed for $\mathrm{CsBr} / \mathrm{PbBr}_{2}$ ratio $\geq 2.0$ (i.e., $\mathrm{CsBr}$-rich solutions). Polycrystalline $\mathrm{CsPbBr}_{3}$ film with additional $\mathrm{CsPb}_{2} \mathrm{Br}_{5}$ phase was observed on the film deposited from the solution with $\mathrm{CsBr} / \mathrm{PbBr}_{2}$ ratio of 0.8. The $\mathrm{CsPb}_{2} \mathrm{Br}_{5}$ peak was disappeared with increasing the $\mathrm{CsBr} / \mathrm{PbBr}_{2}$ ratio and pure $\mathrm{CsPbBr}_{3}$ were observed for films with $\mathrm{CsBr} / \mathrm{PbBr}_{2}$ ratio $\geq 1.0$. Due to the lower trap density, the maximum luminance of the PeLED using the 2.0 $\mathrm{CsBr} / \mathrm{PbBr}_{2}$ solution (named 2-1, $407 \mathrm{~cd} \mathrm{~m}^{-2}$ ) was higher than that of the PeLED utilizing the equimolar $\mathrm{CsBr} / \mathrm{PbBr}_{2}$ solution (named 1-1, $132 \mathrm{~cd} \mathrm{~m}^{-2}$ ). For their device architecture, $\mathrm{F} 8$ was acted as an EIL, which was dissolved in chlorobenzene $(10 \mathrm{mg} / \mathrm{mL})$ and spun onto the $\mathrm{CsPbBr}_{3} \mathrm{EML}$. Hence, the device could be called all solution-processed PeLED [179-183]. However, the devices suffered from a mismatch in the injection barrier of holes and electrons, since approximately $2 \mathrm{~V}$ discrepancy existed between the current turn-on voltage and the turn-on voltage for the electroluminescence.

\subsection{Strategies to Improve the Hole Injection}

Owing to the multilayer device architectures, charge barriers easily exist between the adjacent layers [184-188]. As a consequence, charges are not smoothly transported to the EML in all-inorganic PeLEDs, reducing the probability of exciton generation. In addition, charges can be accumulated at the interface of charge transport layers and EML, leading to the nonradiative recombination [189-192]. Therefore, it is expected that high-performance all-inorganic PeLEDs can be organized via the enhancement of charge injection and transport. In particular, since there is usually a large barrier for the hole transport in all-inorganic PeLEDs, how to effectively improve the hole injection and transport is crucial to the performance. So far, three main strategies have been reported to improve the hole injection and transport, (i) the insertion of an interlayer at the interface of the neighboring layers, forming a step-wise layer for the hole transport; (ii) the control of the energy level alignment by modifying the 
HILs or HTLs; (iii) the use of materials with high hole mobilities [193-198]. With such strategies, suppressed charging perovskites, prevented exciton quenching together with excellent film morphology may be simultaneously obtained, further enhancing the performance of all-inorganic PeLEDs.
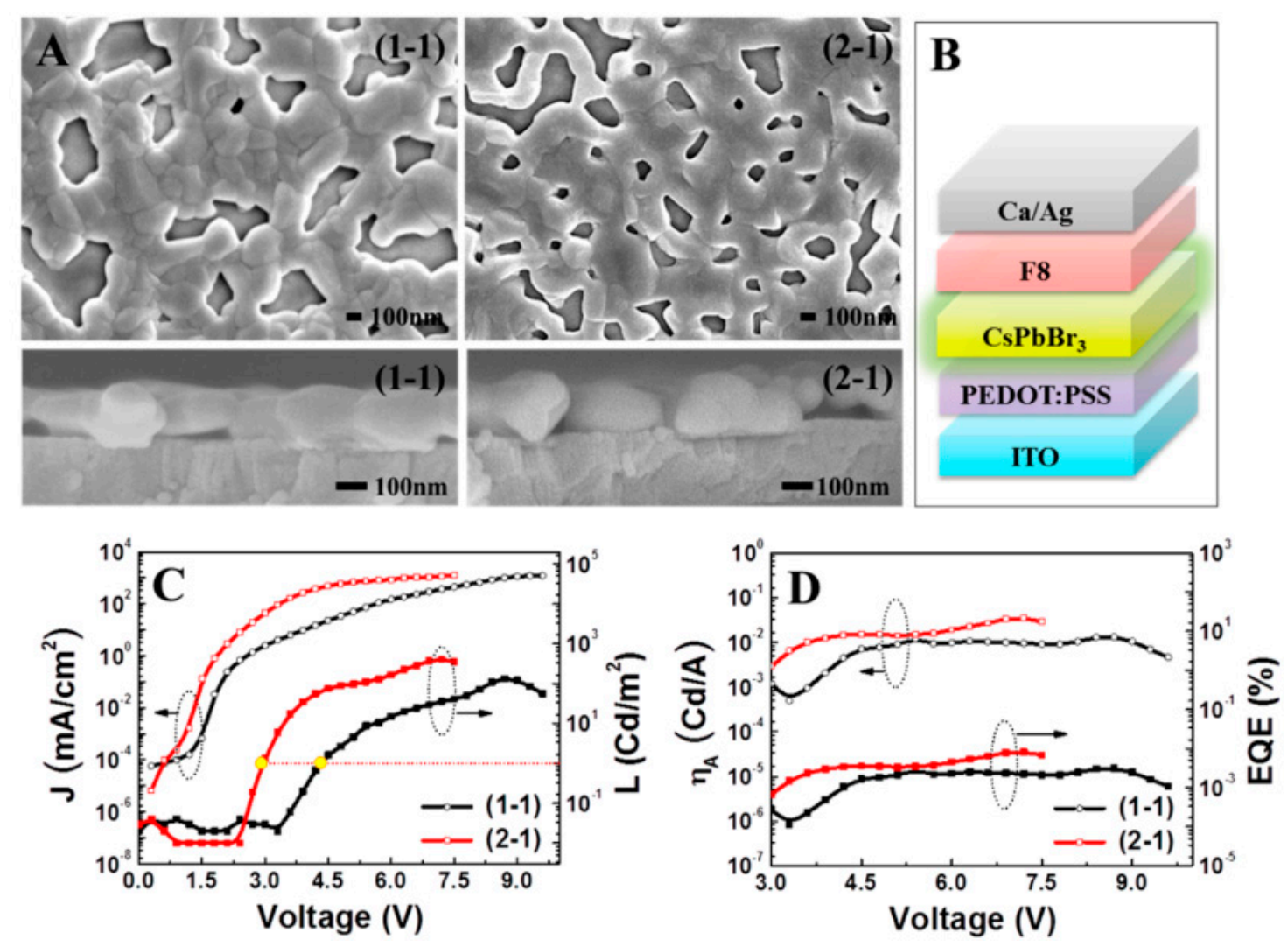

Figure 4. Topographic and cross-sectional images of (1-1) and (2-1) samples (A) together with the generic schematic diagram of the devices $(\mathbf{B})$. Current density and luminescence versus driving voltage curves $(\mathbf{C})$ and current efficiency $\left(\eta_{A}\right)$ and external quantum efficiency (EQE) versus voltage curves (D) of all samples. Reproduced from reference [93], with permission from American Chemical Society, 2015.

For the first strategy, Rogach et al. improved the hole injection by incorporating $\sim 5 \mathrm{~nm}$ PFI between the HTL and perovskite EML, leading to a $0.34 \mathrm{eV}$ increase of the VBM of HTL [72]. As shown in Figure 5, the device architecture was ITO/PEDOT:PSS $(25 \mathrm{~nm}) /$ poly-TPD $(40 \mathrm{~nm}) / \mathrm{CsPbBr}_{3}$ nanocrystal film $(40 \mathrm{~nm}) / \mathrm{TPBI}(40 \mathrm{~nm}) / \mathrm{LiF} / \mathrm{Al}$. With the use of thin PFI, the VBM of poly-TPD HTL was increased, which was beneficial to the hole injection, ensuring efficient radiative recombination of excitons in the EML. Besides, PFI suppressed charging $\mathrm{CsPbBr}_{3}$ emitters, which were formed when $\mathrm{CsPbBr}_{3}$ was directly contacted with poly-TPD since a spontaneous charge transfer process occurred due to the large energy level difference. As a consequence, a three-fold increase in peak brightness reaching $1377 \mathrm{~cd} \mathrm{~m}^{-2}$ was achieved via the insertion of PFI. From the same way, Lee et al. inserted PFI between PEDOT:PSS and $\mathrm{CH}_{3} \mathrm{NH}_{3} \mathrm{PbBr}_{3}$ in the hybrid organic-inorganic PeLEDs, achieving the highest current efficiency of $15.5 \mathrm{~cd} \mathrm{~A}^{-1}$ at that time [199]. In their devices, PFI could facilitate the hole injection, prevent exciton quenching at the PEDOT:PSS/perovskite particle film interface, and induce uniform perovskite films possibly due to the low surface energy $(\sim 23 \mathrm{mN} / \mathrm{m})$ [200]. 
a

b
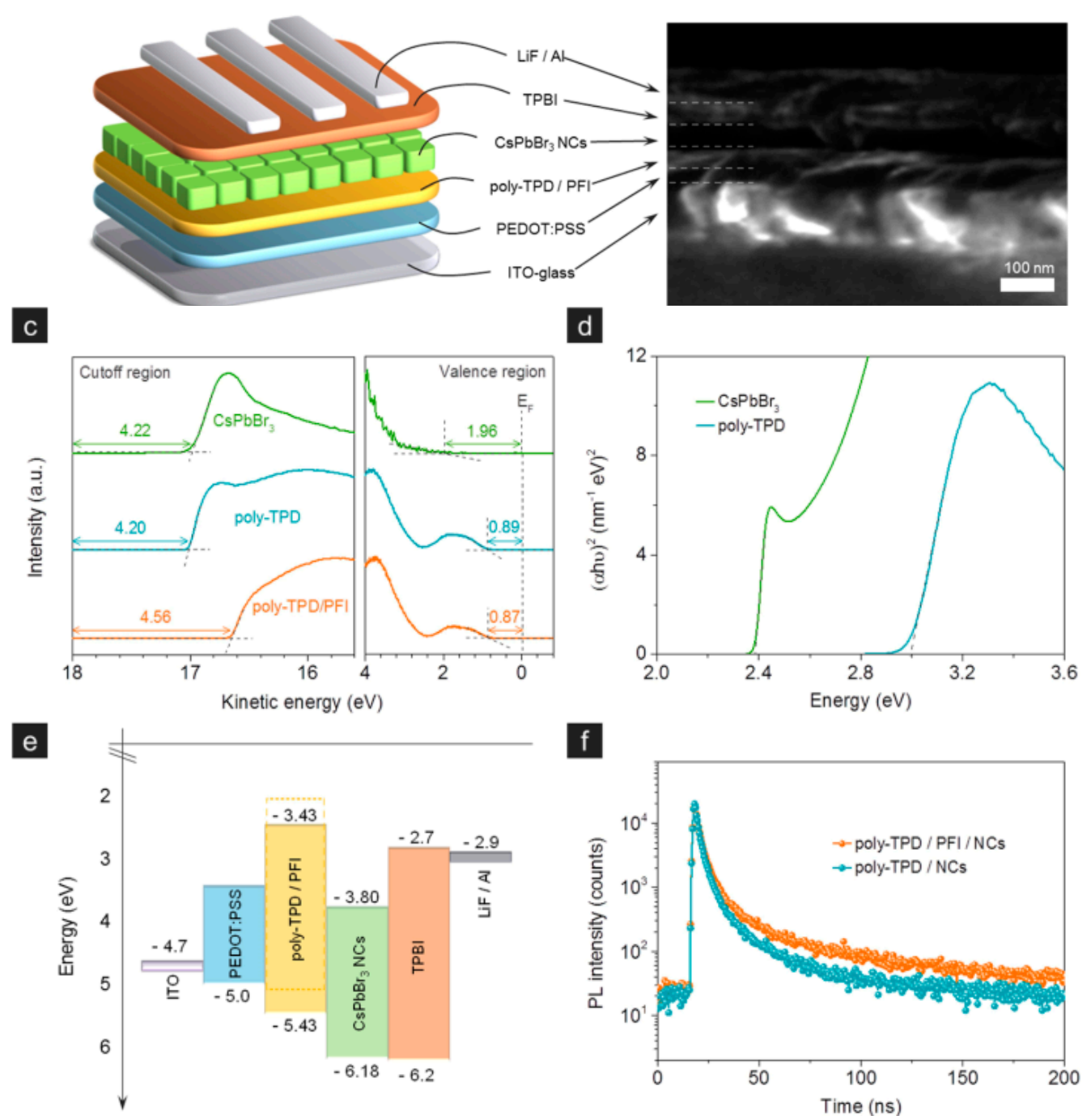

Figure 5. (a) Device structure and (b) cross-sectional SEM image of the PeLED. (c) Ultraviolet photoelectron spectroscopy (UPS) spectra of $\mathrm{CsPbBr}_{3}$, poly-TPD and poly-TPD/PFI film deposited on ITO. (d) Tauc plot of $\mathrm{CsPbBr}_{3}$ and poly-TPD films on quartz substrates. (e) Energy band diagram. (f) Photoluminescence (PL) decay curves of a $\mathrm{CsPbBr}_{3}$ film on a poly-TPD, and as a film on a PFI/poly-TPD. Reproduced from reference [72], with permission from American Chemical Society, 2016.

The introduction of PFI or metal oxides can enhance the performance of PeLEDs, however, such materials may form aggregates and yield to wettability problems with the subsequent deposited perovskites, resulting in electrical shorts and power losses. To alleviate this difficulty, Blom et al. inserted the 2D material black phosphorus (BP) between PEDOT:PSS and $\mathrm{CsPbBr}_{3}$ as a HTL to reduce the injection barrier [201]. BP had a $\mathrm{HOMO}$ of $5.32 \mathrm{eV}$, which lowered the injection barrier by $0.3 \mathrm{eV}$. As shown in Figure 6, the device architecture was ITO/PEDOT:PSS/BP/polycrystalline $\mathrm{CsPbBr}_{3} / \mathrm{TPBi} / \mathrm{LiF} / \mathrm{Al}$, where solution-processable, large and ultrathin $\mathrm{BP}$ flakes with fewer defects were synthesized by electrochemical exfoliation of bulk BP. By virtue of BP, the EQE was enhanced to $2.8 \%$, which was four-fold higher than that of control device without BP $(0.07 \%)$. The enhanced performance was attributed to the fact that BP decreased the hole injection barrier and gave rise to uniform growth of the perovskite, resulting in a higher injected hole current and lower leakage current and nonradiative losses, respectively. 
a

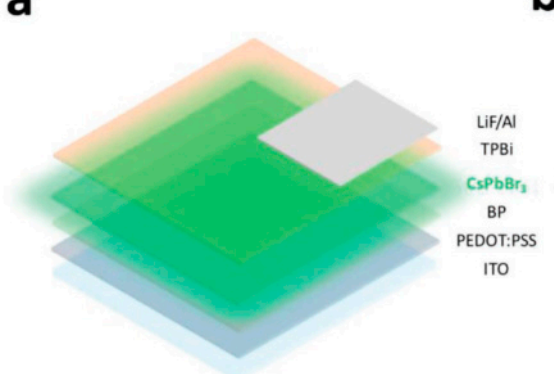

b

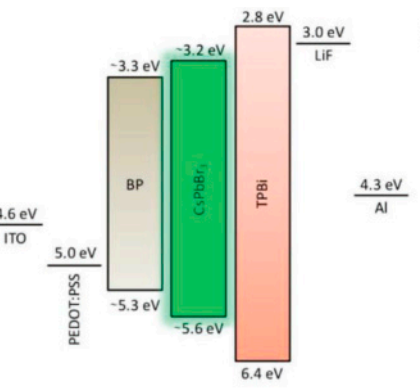

C

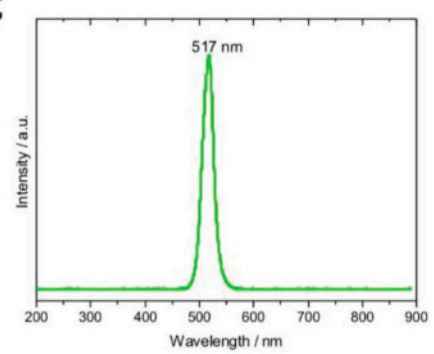

Figure 6. (a) Schematic illustration of the device architecture and (b) the energy band alignment diagram. (c) EL spectrum at 6 V. Reproduced from reference [201], with permission from John Wiley and Sons, 2018.

PEDOT:PSS is a well-known HIL in solution-processed LEDs due to its optical and electrical properties, such as smoothing the surface of substrates, reducing the current leakage and facilitating the hole injection [202-204]. However, there is still a hole barrier between PEDOT:PSS and HTLs, reducing the hole transport. To overcome this issue, Kido et al. modified PEDOT:PSS with nafion to greatly enhance the work function from 4.72 to $5.27 \mathrm{eV}$, which was close to the HOMO of the poly-TPD $(5.31 \mathrm{eV})$ [47]. Hence, the hole injection barrier between modified PEDOT:PSS and poly-TPD is quite small. As shown in Figure 7, the device architecture was ITO $(130 \mathrm{~nm}) /$ modified PEDOT:PSS $(40 \mathrm{~nm}) /$ poly-TPD $(20 \mathrm{~nm}) / \mathrm{CsPbBr}_{3} / \mathrm{TPBi}(50 \mathrm{~nm}) /$ lithium 8-quinolate (Liq, $\left.1 \mathrm{~nm}\right) / \mathrm{Al}(100 \mathrm{~nm})$, where the excess ligands of $\mathrm{CsPbBr}_{3}$ QDs were washed by butanol $(\mathrm{BuOH})$, hexane and ethylacetate (AcOEt) and butylacetate $(\mathrm{AcOBu})$. With such effective device architecture by controlling the energy level alignment, the PeLED based on $\mathrm{CsPbBr}_{3}$ QDs washed with AcOBu exhibited a maximum power efficiency of $31.7 \mathrm{~lm} \mathrm{~W} \mathrm{~W}^{-1}$ and EQE of $8.73 \%$, which was the highest among all-inorganic PeLEDs at that time. Later, Kido et al. also used the modified PEDOT:PSS with nafion to develop PeLEDs, achieving an EQE of $8.08 \%$ for the device using $\mathrm{CsPbBr}_{3}$ with a short ligand didodecyl dimethyl ammonium bromide (DDAB) [48]. Thus, the control of the energy level alignment of HILs or HTLs is an effective strategy to enhance the performance.
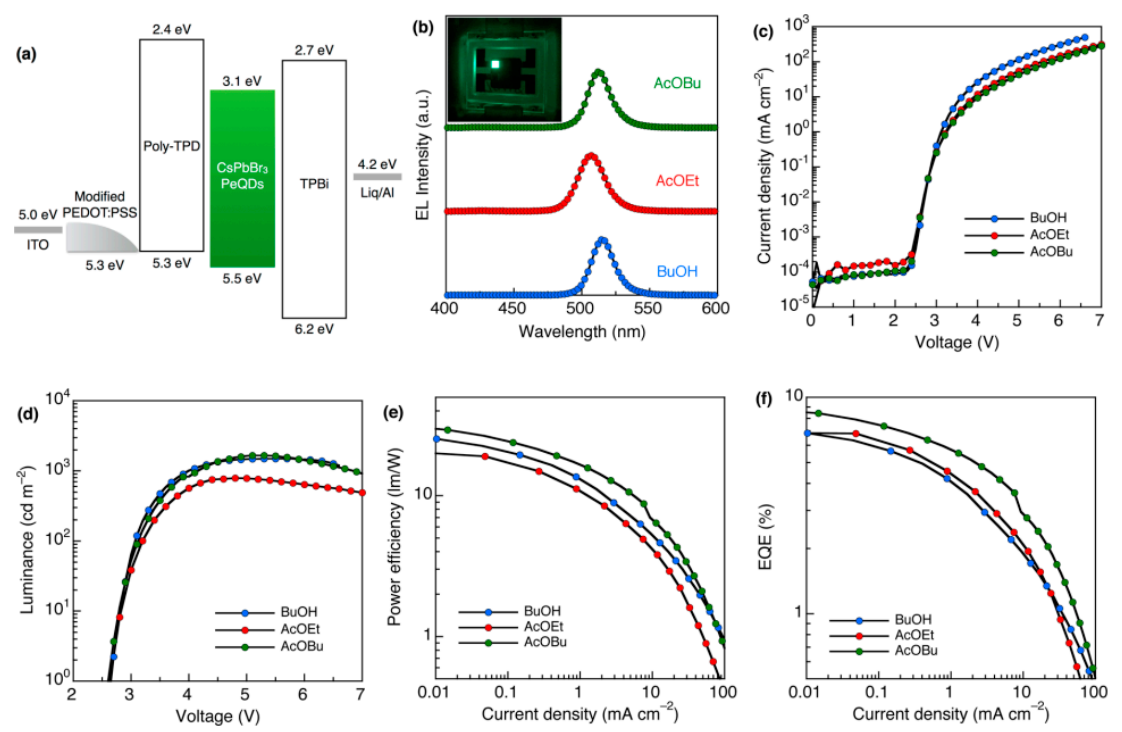

Figure 7. PeLEDs performance. (a) Energy diagram. (b) EL spectra of a device at $25 \mathrm{~mA} \mathrm{~cm}{ }^{-2}$. Inset: Emission image of the device. (c) Current density-voltage characteristics, (d) luminance-voltage characteristics, (e) power efficiency-current density characteristics and (f) EQE-current density characteristics. Reproduced from reference [47], with permission from American Chemical Society, 2017. 
The use of charge transport materials with high mobility is another effective strategy to boost the charge injection and transport, which has been broadly exploited in various types of LEDs [205-210]. In the case of all-inorganic PeLEDs, Zeng et al. replaced the PVK HTL with the poly-TPD HTL, achieving a 2.6-fold higher EQE [49]. As shown in Figure 8, the device architecture was ITO/PEDOT:PSS $(30 \mathrm{~nm}) / \mathrm{HTL}(40 \mathrm{~nm}) / \mathrm{CsPbBr}_{3} / \mathrm{TPBi}(40 \mathrm{~nm}) / \mathrm{LiF}(1 \mathrm{~nm}) / \mathrm{Al}(100 \mathrm{~nm})$, where the HTL was PVK or poly-TPD. The enhancement of EQE for the poly-TPD based device could be attributed to the fact that the hole mobility of poly-TPD $\left(\sim 1 \times 10^{-4} \mathrm{~cm}^{2} \mathrm{~V}^{-1} \mathrm{~s}^{-1}\right)$ is two orders of magnitude higher than that of PVK $\left(\sim 1 \times 10^{-6} \mathrm{~cm}^{2} \mathrm{~V}^{-1} \mathrm{~s}^{-1}\right)$, which improved the hole injection. With the selection of more effective solvents for the treatment of $\mathrm{CsPbr}_{3}$ QDs (appropriate hexane/ethyl acetate treating cycles), the EQE was enhanced to $6.27 \%$. Furthermore, Kido et al. used the almost similar device architecture (i.e., ITO/PEDOT:PSS/poly-TPD/perovskites/TPBi/Liq/Al) with efficient red emitter $\mathrm{CsPb}(\mathrm{Br} / \mathrm{I})_{3}$, realizing the first all-inorganic PeLED with EQE of $>20 \%$ [36].
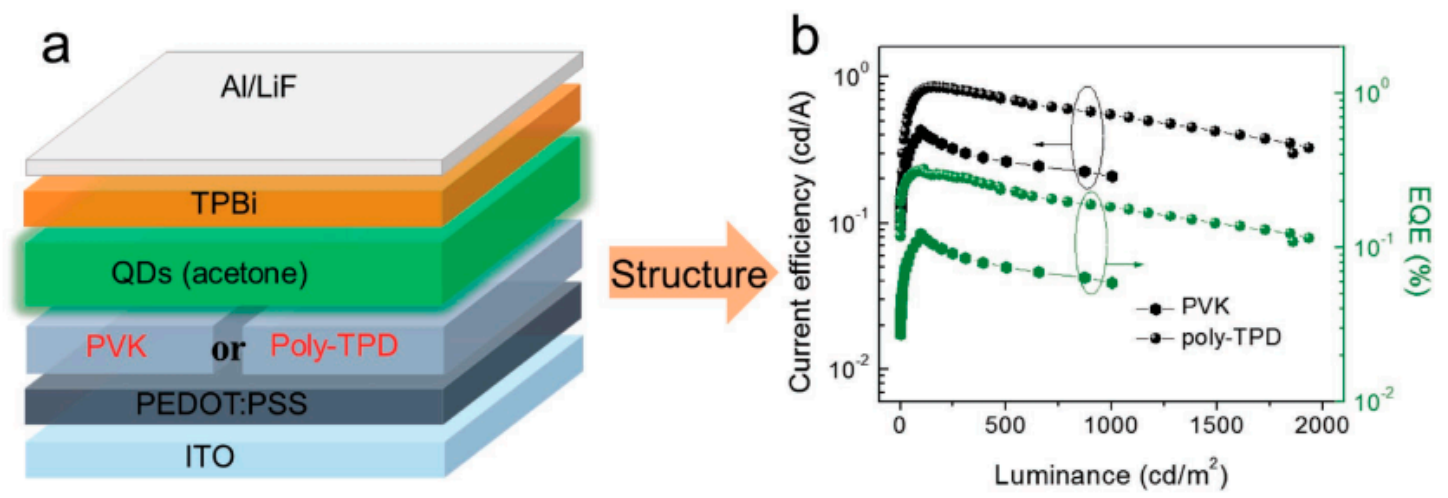

Figure 8. Contributions from selection of hole transport layer (HTL). (a) Schematic illustration of device for structure optimization and (b) corresponding comparison of current efficiency and EQE. Reproduced from reference [49], with permission from John Wiley and Sons, 2016.

\subsection{Approaches to Enhance the Electron Injection}

As mentioned above, the electron transport between the organic ETLs and the EML is usually barrier-free for all-inorganic PeLEDs with normal device architectures. In terms of inorganic ETLs (e.g., the most commonly used $\mathrm{ZnO}$ ), the electron injection efficiency should be considered due to the barrier existing between the ETL and perovskite EMLs [211]. To enhance the electron injection, some approaches were proposed, including (i) the exploitation of impurity doped inorganic ETLs to optimize the energy band alignment, (ii) the employment of interfacial engineering between inorganic ETLs and perovskite EMLs.

For the first approach, Shi et al. enhanced the electron injection through energy band engineering of carrier injectors by $\mathrm{Mg}$ incorporation and the thickness optimization, attaining an inverted all-inorganic PeLED with the maximum EQE of 2.39\% [212]. As shown in Figure 9, the device architecture was double-polished c- $\mathrm{Al}_{2} \mathrm{O}_{3}$ substrates/patterned low-resistance $\mathrm{n}^{+}-\mathrm{GaN}(2 \mu \mathrm{m}) / \mathrm{n}-\mathrm{Mg}_{0.38} \mathrm{Zn}_{0.62} \mathrm{O}$ $(45 \mathrm{~nm}) / \mathrm{CsPbBr}_{3}$ QDs $(55 \mathrm{~nm}) / \mathrm{p}-\mathrm{Mg}_{0.23} \mathrm{Ni}_{0.77} \mathrm{O}(80 \mathrm{~nm}) / \mathrm{Au}(30 \mathrm{~nm})$, in which $\mathrm{n}^{+}-\mathrm{GaN}$ was used as the electron source, conducting template and a transparent window. Due to the matched electron affinity with $\mathrm{CsPbBr}_{3}$ and a deep VBM, n-type $\mathrm{MgZnO}$ was deemed as the electron-injection and hole-blocking layer. Specifically, the decreased electron affinity from $-3.6 \mathrm{eV}(\mathrm{ZnO})$ to $-3.25 \mathrm{eV}$ $\left(\mathrm{Mg}_{0.38} \mathrm{Zn}_{0.62} \mathrm{O}\right)$ favored an almost barrier-free electron injection process. Besides, the VBM above $-7.2 \mathrm{eV}$ for $\mathrm{Mg}_{0.38} \mathrm{Zn}_{0.62} \mathrm{O}$ implied a favorable hole-blocking effect and thereby provided a leakage suppression. Analogously, an $\mathrm{Mg}^{2+}$ content of $\sim 23 \%$ (mole percent) was alloyed in the $\mathrm{NiO}$ film to adjust its conduction and valence bands for a matched energy level with $\mathrm{CsPbBr}_{3}$, guaranteeing the hole injection. Thus, an efficient and stable PeLED was developed. Owing to MgZnO possessing effective electron injection and hole confining ability, Shi et al. then used it to prepare all-inorganic PeLEDs with the normal architecture of $\mathrm{ITO} / \mathrm{p}-\mathrm{NiO} / \mathrm{CsPbBr}_{3} \mathrm{QDs} / \mathrm{Mg}_{0.2} \mathrm{Zn}_{0.8} \mathrm{O} / \mathrm{Al}$, achieving an EQE 
of 3.79\% [213]. Furthermore, Tan et al. for the first time used the solution-processed $\mathrm{ZnMgO}$ as the ETL in a normal device architecture of ITO/NiOx/ $/ \mathrm{SPBr}_{3} / \mathrm{ZnMgO} / \mathrm{Al}$, obtaining a maximum luminance of $17017 \mathrm{~cd} \mathrm{~m}^{-2}$ and a current efficiency of $3.41 \mathrm{~cd} \mathrm{~A}^{-1}$ [214]. Additionally, lithium-doped $\mathrm{TiO}_{2}$ has also been demonstrated to be an excellent ETL in all-inorganic PeLEDs $[215,216]$.
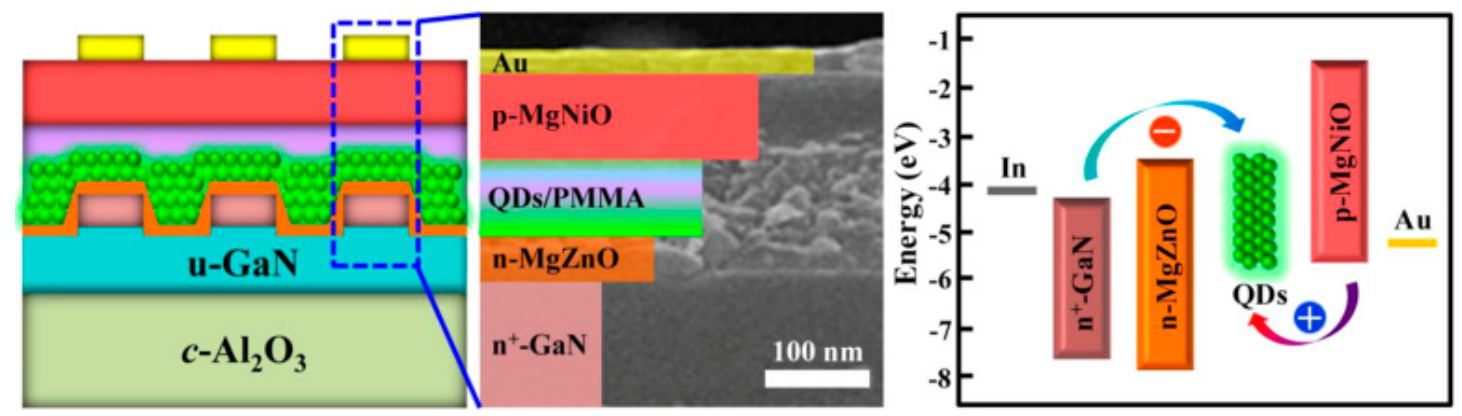

Figure 9. Schematic diagram, cross-sectional SEM image and energy band alignment of the PeLEDs. Reproduced from reference [212], with permission from American Chemical Society, 2017.

For the enhancement of interfacial engineering, a thin multifunctional layer (e.g., polyethyleneimine (PEI), polyethylenimine ethoxylated (PEIE)) is generally introduced between inorganic ETLs and EMLs $[217,218]$. With such interfacial layer, not only the perovskite film formation quality during solution processing can be enhanced, but also the work function of cathode contacts is lowered. Huang et al. for the first time investigated this approach in hybrid organic-inorganic PeLEDs with the device architecture of ITO/PEI-modified $\mathrm{ZnO}(20 \mathrm{~nm}) / \mathrm{CH}_{3} \mathrm{NH}_{3} \mathrm{PbI}_{3-\mathrm{x}} \mathrm{Cl}_{\mathrm{x}}$ $(50 \mathrm{~nm}) /$ poly $(9,9-$ dioctyl-fluorene-co- $N$-(4-butylphenyl)diphenylamine) (TFB, $25 \mathrm{~nm}$ )/molybdenum oxide $\left(\mathrm{MoO}_{\mathrm{x}}, 8 \mathrm{~nm}\right) / \mathrm{Au}(100 \mathrm{~nm})$ [219].

In the case of all-inorganic PeLEDs, Yu et al. also demonstrated that the use of PEI between the ZnO ETL and the EML was effective to realize high-efficiency devices, since PEI facilitated the electron injection and prevented the charging of emitters [52]. After the PEI modification, a reduction of $0.44 \mathrm{eV}$ in the CBM of small $\mathrm{ZnO}$ nanocrystals $(\sim 2 \mathrm{~nm})$ was achieved, providing an efficient electron injection. As shown in Figure 10, the device architecture was ITO/PEI-modified $\mathrm{ZnO}(50 \mathrm{~nm}) / \mathrm{CsPb}(\mathrm{Br} / \mathrm{I})_{3}$ $(60 \mathrm{~nm}) / 4,4^{\prime}$-bis(carbazole-9-yl)biphenyl (CBP)/4,4', $4^{\prime \prime}$ - tris(carbazol-9-yl)triphenylamine (TCTA) $(50 \mathrm{~nm}) / \mathrm{MoO}_{\mathrm{x}} / \mathrm{Au}$, in which the double HTL (CBP and TCTA) ensure enough hole injection. As a result, the PeLED gave an EQE up to $6.3 \%$, which is the highest value reported among perovskite nanocrystal LEDs at that time. Since PEI is effective to enhance the electron injection and maintain charge neutrality of $\mathrm{CsPbX}_{3}$ emitters, $\mathrm{Yu}$ et al. then used a more efficient red emitter, $\mathrm{PbS}$ capped $\mathrm{CsPbI}_{3}$, in the similar device architecture of ITO/PEI-modified $\mathrm{ZnO} / \mathrm{CsPbI}_{3} / \mathrm{TCTA} / \mathrm{MoO}_{\mathrm{x}} / \mathrm{Au}$, exhibiting a peak EQE of $11.8 \%$ [53]. More recently, Yu et al. applied the architecture of Ag cathode/PEI-modified $\mathrm{ZnO} / \mathrm{CsPb}_{3} / \mathrm{TCTA} / \mathrm{MoO}_{\mathrm{x}} / \mathrm{Au}$ onto a photopolymer flexible substrate, attaining a flexible all-inorganic PeLED with the EQE of $8.2 \%$ [54].

\subsection{Schemes to Increase the Charge Balance}

Since EQE is directly decided by the charge balance, the increase of charge balance is essential to high-performance all-inorganic PeLEDs. In particular, excess electrons occur easily when organic ETLs are used because of the barrier-free electron injection behavior between organic ETLs and all-inorganic perovskite EMLs. To resolve this issue, the enhancement of hole injection is conducive [220-225]. Alternatively, the reduction of electron injection is also useful. This scheme is very flexible, since plenty of means can be utilized to reduce the electron injection, such as the insertion of an insulating layer between the ETL and EML [42], the use of electron transport materials with low mobilities [226], the employment of ETLs with thick thickness [227] and the introduction of HTL between the ETL and 
EML [228]. As these schemes are well reported in various kinds of LEDs, it is also possible to develop all-inorganic PeLEDs with such schemes.
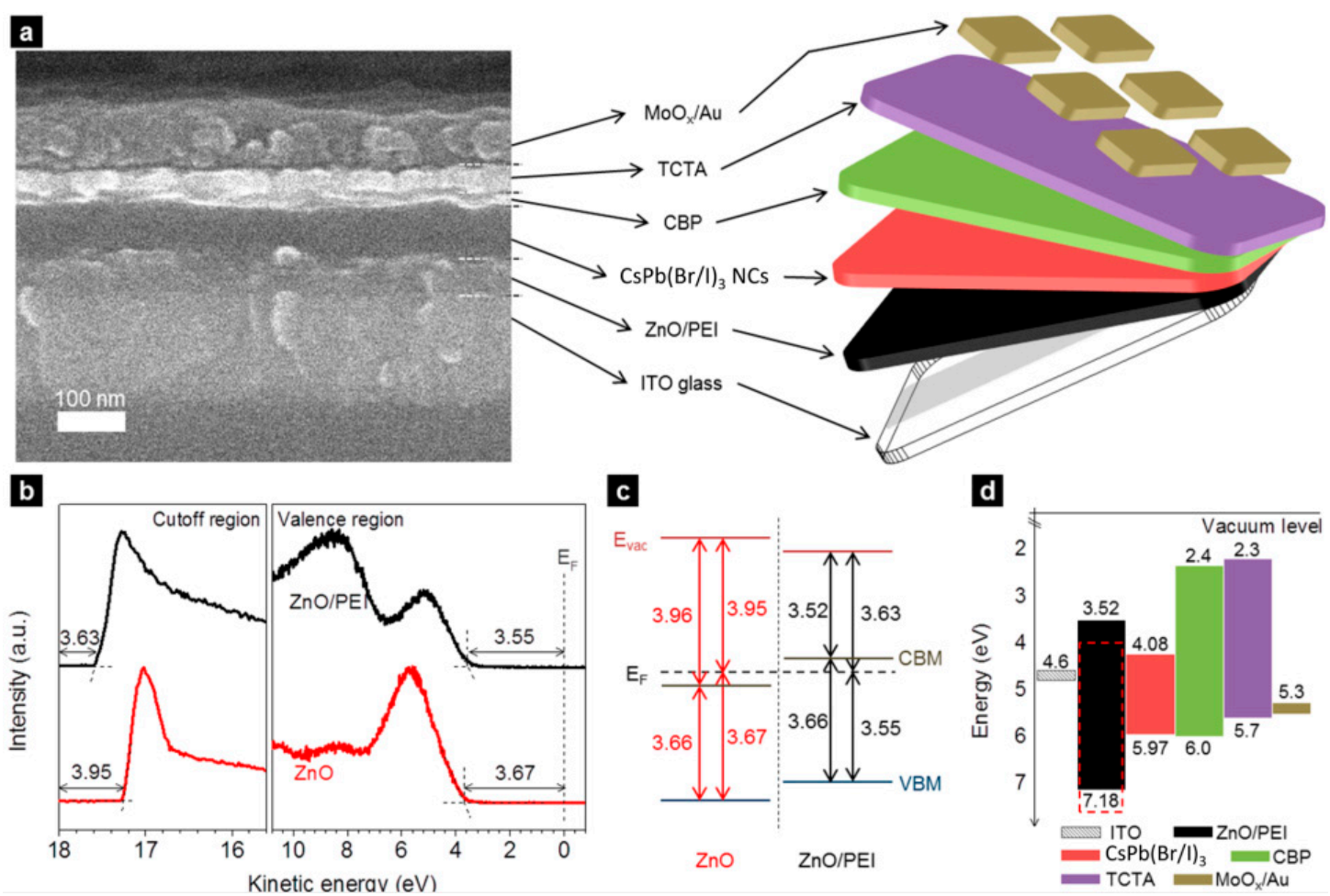

c

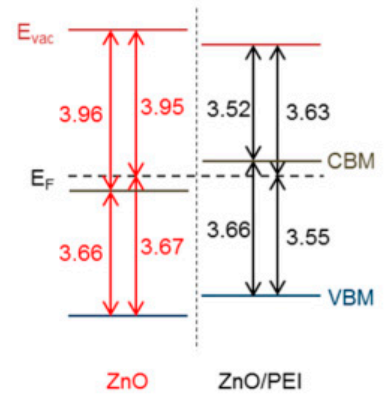

d

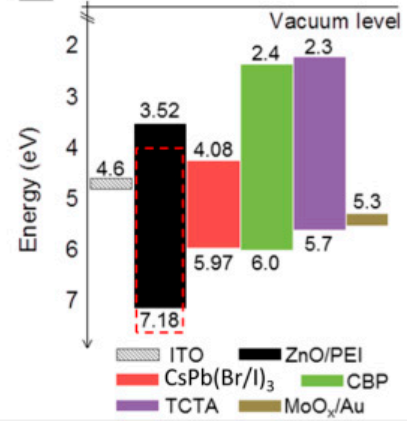

Figure 10. Structure and energy levels. (a) Device structure and cross-sectional SEM image of a PeLED. (b) UPS spectra of $\mathrm{ZnO}$ and $\mathrm{ZnO} / \mathrm{PEI}$ film deposited on ITO glass substrate. (c) Energy level diagram. (d) Overall energy band diagram of the LED structure. The red dash line represents for energy levels of ZnO. Reproduced from reference [52], with permission from American Chemical Society, 2016.

To balance the charges, Liu et al. reduced the electron injection by adopting a proper ETL in all-inorganic PeLEDs [229]. In detail, tris(8-hydroxyquinoline) aluminum ( $\mathrm{Alq}_{3}$ ) was incorporated into TPBi to form an ETL TPBi/Alq ${ }_{3} / \mathrm{TPBi}$, simultaneously enabling charge balance and confinement. The green PeLED with the device architecture of ITO/PEDOT:PSS $(40 \mathrm{~nm}) / \mathrm{PVK}(10 \mathrm{~nm}) / \mathrm{CsPbBr}_{3}$ $\left(20 \mathrm{~nm}, 10 \mathrm{mg} \mathrm{mL}{ }^{-1}, 2000 \mathrm{rpm}, 45 \mathrm{~s}\right) / \mathrm{TPBi}(15 \mathrm{~nm}) / \mathrm{Alq}_{3}(10 \mathrm{~nm}) / \mathrm{TPBi}(10 \mathrm{~nm}) / \mathrm{Cs}_{2} \mathrm{CO}_{3}(1 \mathrm{~nm}) / \mathrm{Al}$ $(100 \mathrm{~nm})$ exhibited a maximum EQE of $1.43 \%$, which was $191 \%$, higher than that of PeLEDs with conventional ETL TPBi $(35 \mathrm{~nm})$. The maximum current density of the PeLED with TPBi/Alq $3 / \mathrm{TPBi}$ was $186 \mathrm{~mA} \mathrm{~cm}^{-2}$. The highest EQE was obtained at a very low current density of $0.44 \mathrm{~mA} \mathrm{~cm}^{-2}$, which is a common issue for all-inorganic PeLEDs [47]. As shown in Figure 11, since the electron mobility of $\mathrm{Alq}_{3}$ $\left(1.4 \times 10^{-6} \mathrm{~cm}^{2} \mathrm{~V}^{-1} \mathrm{~s}^{-1}\right)$ was almost equal to the hole mobility of PVK $\left(1.0 \times 10^{-6} \mathrm{~cm}^{2} \mathrm{~V}^{-1} \mathrm{~s}^{-1}\right)$ while the electron mobility of TPBi $\left(3.3 \times 10^{-5} \mathrm{~cm}^{2} \mathrm{~V}^{-1} \mathrm{~s}^{-1}\right)$ and Bphen $\left(3.9 \times 10^{-4} \mathrm{~cm}^{2} \mathrm{~V}^{-1} \mathrm{~s}^{-1}\right)$ was much higher than the hole mobility of $\mathrm{PVK}$, the incorporation of $\mathrm{Alq}_{3}$ could impede the electron transport in order to balance the holes. In other words, the $\mathrm{Alq}_{3}$ reduced the number of electrons passing through the ETL. As a result, a relatively appropriate number of electrons could reach the $\mathrm{CsPbBr}_{3} \mathrm{EML}$. On the other hand, TPBi could confine the hole transport, further guaranteeing the performance. However, it is deserved to point out that some perovskite papers that discuss deliberate charge imbalance being okay, since the charge imbalance may result in good performance (e.g., ultralow voltages) [86]. 
(a)

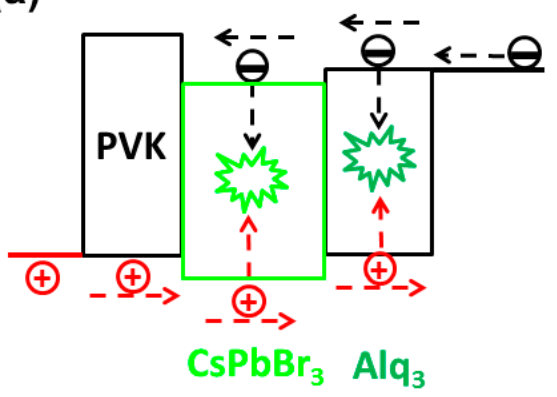

(b)



(c)



(d)



Figure 11. The working mechanisms of $\mathrm{CsPbBr}_{3}$ PeLEDs: (a) Device with $\mathrm{Alq}_{3} \mathrm{ETL}$, (b) device with TPBi ETL, (c) device G3 with Bphen ETL and (d) device with TPBi/Alq 3 /TPBi ETL. The red and black arrows represented the hole and electron transport, respectively. Reproduced from reference [229], with permission from John Wiley and Sons, 2018.

\subsection{Methods to Decrease the Charge Leakage}

In some cases, holes and electrons can escape from the perovskite EMLs to the ETL and HTL, respectively. For example, holes may arrive at the ETL if there is no hole blocking layer or the energy level of ETLs is not deep enough compared with that of perovskite EMLs. On the other hand, electrons may reach the HTL when no electron blocking layer exists or the energy level of HTLs is not shallow enough. To loosen these bottlenecks, the addition of charge blocking layer or the charge transport layer with high charge blocking capability is required [230-234]. In addition, 3D perovskite film is prone to be rough or discontinuous because of the crystalline property, resulting in strong leakage current [235-239]. Thus, the performance of all-inorganic PeLEDs will be deteriorated due to the poor film morphology.

To form a dense and uniform perovskite film with full coverage, Wu et al. proposed an "insulator-perovskite-insulator" device architecture to tailor PeLEDs [240]. As shown in Figure 12, the architecture of Device $\mathrm{C}$ was ITO/LiF $(4 \mathrm{~nm}) /$ perovskite/LiF $(8 \mathrm{~nm}) / \mathrm{Bphen}(60 \mathrm{~nm}) / \mathrm{LiF}(0.8 \mathrm{~nm}) / \mathrm{Al}$ $(100 \mathrm{~nm})$, where perovskite was sandwiched between the two LiF insulating layers. For various types of perovskites, the proposed device architecture could simultaneously induce charges into perovskite crystals, block current leakage via pinholes in the perovskite film and avoid exciton quenching. Consequently, the EQE of $\mathrm{FAPbBr}_{3}$ PeLEDs was increased to $5.53 \%$, which was much higher than that of the control device with the conventional HIL (PEDOT:PSS, Device A) or PEDOT:PSS/PVK $(0.174 \%$, Device B). For the case of $\mathrm{MAPbBr}_{3}$ PeLEDs, the EQE was increased from $0.057 \%$ to $2.36 \%$. In terms of the all-inorganic PeLEDs, both current efficiency and lifetime of $\mathrm{CsPbBr}_{3}$ PeLEDs were improved from 1.42 and $4 \mathrm{~h}$ to $9.86 \mathrm{~cd} \mathrm{~A}^{-1}$ and $96 \mathrm{~h}$ compared with the control device. 

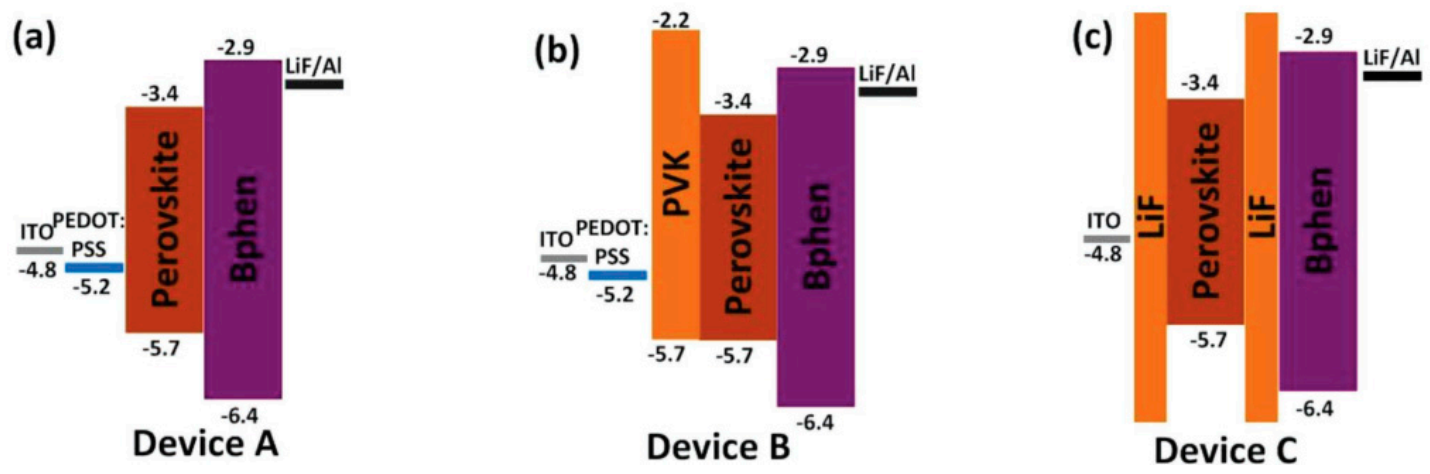

Figure 12. The energy level diagram of three types of PeLEDs. The active layers were PEDOT:PSS/ perovskite/Bphen for Device A (a), PEDOT:PSS/PVK/perovskite/Bphen for Device B (b), and LiF/ perovskite/LiF/Bphen for Device C (c). Reproduced from reference [240], with permission from John Wiley and Sons, 2018.

\section{Summary and Outlook}

Since all-inorganic PeLEDs can show high efficiency, low driving voltage, bright luminance, outstanding color-purity and long lifetime, the excellent characteristics have rendered that all-inorganic PeLEDs are very promising for the new-generation displays and lighting. Nowadays, the efficiency of state-of-the-art all-inorganic PeLEDs can be comparable to that of the best OLEDs and CdSe-based QD-LEDs. In this review, we have mainly focused on recent advances in the device engineering of all-inorganic PeLEDs. Particularly, we have emphasized the emergence of all-inorganic PeLEDs, strategies to improve the hole injection, approaches to enhance the electron injection, schemes to increase the charge balance and methods to decrease the charge leakage. The detailed performances for all-inorganic PeLEDs have been described in Table 1.

Table 1. Summarized performances for representative all-inorganic PeLEDs.

\begin{tabular}{|c|c|c|c|c|c|}
\hline PeLEDs $^{a}$ & $\begin{array}{c}V_{\text {on }}{ }^{b} \\
(v)\end{array}$ & $\begin{array}{c}\mathrm{EQE}_{\max } \mathrm{c} \\
(\%)\end{array}$ & $\begin{array}{l}P E_{\max }{ }^{d} \\
\left(\operatorname{lm} W^{-1}\right)\end{array}$ & $\begin{array}{l}\mathrm{CE}_{\max } \mathrm{e} \\
\left(\mathrm{cd} A^{-1}\right)\end{array}$ & $\begin{array}{c}L_{\max } f \\
\left(\mathrm{~cd} \mathrm{~m}^{-2}\right)\end{array}$ \\
\hline Ref. [19] & 4.2 & 0.12 & 0.18 & 0.43 & 946 \\
\hline Ref. [47] & 2.6 & 8.73 & 31.7 & 26.2 & 1660 \\
\hline Ref. [49] & 3.4 & 6.27 & 5.24 & 13.3 & 15185 \\
\hline Ref. [52] & 1.9 & 6.3 & 4.05 & 3.4 & 2216 \\
\hline Ref. [72] & 2.5 & 0.06 & - & 0.19 & 1337 \\
\hline Ref. [93] & 3.0 & 0.008 & - & 0.035 & 407 \\
\hline Ref. [201] & - & 2.8 & - & 12.3 & 20636 \\
\hline Ref. [212] & 3.0 & 2.39 & - & 2.25 & 3809 \\
\hline Ref. [229] & 4.8 & 1.43 & 1.84 & 4.69 & 452 \\
\hline Ref. [240] & - & 2.99 & - & 9.86 & $\sim 13000$ \\
\hline
\end{tabular}

After approximate five years of development, the performance of all-inorganic PeLEDs has been step-by-step enhanced. In addition to the optimization of perovskite emitters, the PeLED performance has been greatly boosted by the innovation of device engineering. Currently, all-inorganic PeLEDs are also being explored in flexible as well as transparent optoelectronics, which further widen their general applications [241-243]. In addition, it can be easily predicted that all-inorganic PeLEDs will show higher performance by virtue of effective outcoupling technologies [244-247], despite negligible attention has been paid on the improvement of the outcoupling factor thus far. Moreover, compared with OLEDs and CdSe-based QD-LEDs, the outstanding color-purity of all-inorganic PeLEDs is more desirable for displays [248-250]. 
Nowadays, there are still many challenges hindering the real commercialization of all-inorganic PeLEDs, such as the efficiency, efficiency roll-off, toxicity and particularly for the operational stability. For the issue of efficiency, although the EQE of all-inorganic PeLEDs have been demonstrated to show $>20 \%$, the current efficiency and power efficiency are still not comparable to those of the best OLEDs and CdSe-based QD-LEDs [251-253]. Besides, the efficiency of blue all-inorganic PeLEDs is urgently needed to be enhanced, considering the highest EQE of blue device is only $1.9 \%$ [55]. To boost the efficiency, the charge injection, transport, balance and leakage should be carefully manipulated, which is also beneficial to the efficiency roll-off, color stability and lifetime. To solve the issue of toxicity, lead-free all-inorganic perovskites are helpful, although their performance is not satisfactory enough [245-258].

For the issue of lifetime, it is a key factor to determine whether all-inorganic PeLEDs can meet the demand of the commercial demands. In general, the lifetime of $\geq 10000 \mathrm{~h}$ at $\geq 1000 \mathrm{~cd} \mathrm{~m}^{-2}$ is required for the commercial solid-state lighting products and $\geq 100000 \mathrm{~h}$ at $\geq 100 \mathrm{~cd} \mathrm{~m}^{-2}$ is needed for the display applications [259-261]. Hence, there is still much room to prolong the lifetime. Previously, some effective approaches have been reported to enhance the stability of all-inorganic perovskite materials, including resistance to moisture and oxygen. For example, Zou et al. demonstrated a method to improve the formation energies of perovskite lattices by doping $\mathrm{Mn}^{2+}$ into $\mathrm{CsPbX}_{3}$ QDs, achieving stable $\mathrm{CsPbX}_{3}$ even at high temperatures up to $200{ }^{\circ} \mathrm{C}$ under ambient air conditions [262]. Ding et al. reported an approach to prepare stable and water-soluble $\mathrm{CsPbX} / \mathrm{SiO}_{2}$ nanocomposites by encapsulating the $\mathrm{CsPbX}_{3}$ QDs into silica nanoplates, where the application of $\mathrm{CsPbX}_{3} / \mathrm{SiO}_{2}$ in white LEDs and cell imaging showed ultrastability and high biocompatibility [263]. Zhu et al. provided a scheme to improve the stability of $\mathrm{CsPbr}_{3}$ nanocrystals film by depositing $\mathrm{Al}_{2} \mathrm{O}_{3}$ on nanocrystals film surface for via plasma enhanced atomic layer deposition [264], where the dense $\mathrm{Al}_{2} \mathrm{O}_{3}$ film also exhibited an encapsulation effect [265]. Shi et al. presented an approach to combine localized surface plasmons and core/shell nanostructure configuration in a single PeLED, where the PeLEDs without encapsulation presented a substantially improved operation stability against water and oxygen degradation (30-day storage in air ambient, $85 \%$ humidity) [266]. Another effective approach is the hybridization of $\mathrm{CsPb}_{3}$ with other matrix materials (e.g., synthesizing a chemically and structurally stable $\mathrm{CsPbBr}_{3}$ perovskite material by using polymer nanofiber as the protective layer [267], presenting a high molecular weight polymer matrix (polymethylmethacrylate, $\mathrm{PMMA}$ ) to incorporate into $\mathrm{CsPbBr}_{3}$ QDs to improve its stability and maintain excellent optical properties [268]). Apart from the exploration of stable perovskite emitters, the further enhancement of device engineering is also urgently necessary (e.g., the use of stable inorganic charge transport layers, the exploitation of insulators, the introduction of advanced encapsulation techniques) [269-274]. After solving the mentioned issues, the prospect for mass production for all-inorganic PeLEDs will be bright and the proposed solutions are also beneficial to the related optoelectronic fields [275-279]. In particular, since the design concept of sensors [280-282] and photodetectors [283-285] are somewhat similar to that of LEDs, the new-emerging all-inorganic perovskite materials have also been extensively investigated for these applications.

Author Contributions: D.L. and B.L. conceived the idea; D.L. and B.L. wrote the paper; Q.C. and M.Z. advised the paper; Y.Q. and B.L. supervised the project. All authors reviewed the paper.

Funding: The authors are grateful to the National Natural Science Foundation of China (Grant No. 61704034), the Pearl River S\&T Nova Program of Guangzhou (Grant No. 201906010058), the Key Platforms and Research Projects of Department of Education of Guangdong Province (Grant No. 2016KTSCX034), the Guangdong Science and Technology Plan (Grant No. 2017B010123002) and the Natural Science Foundation of Guangdong Province (Grant Nos. 2018A0303130199 and 2017A030313632).

Conflicts of Interest: The authors declare no conflict of interest.

\section{References}

1. Lee, M.M.; Teuscher, J.; Miyasaka, T.; Murakami, T.N.; Snaith, H.J. Efficient Hybrid Solar Cells Based on Meso-Superstructured Organometal Halide Perovskites. Science 2012, 338, 643-647. [CrossRef] [PubMed] 
2. Luo, J.; Im, J.H.; Mayer, M.T.; Schreier, M.; Nazeeruddin, M.K.; Park, N.G.; Tilley, S.D.; Fan, H.J.; Grätzel, M. Water photolysis at $12.3 \%$ efficiency via perovskite photovoltaics and Earth-abundant catalysts. Science 2014, 345, 1593-1596. [CrossRef] [PubMed]

3. Jeon, N.J.; Noh, J.H.; Yang, W.S.; Kim, Y.C.; Ryu, S.; Seo, J.; Seok, S.I. Compositional engineering of perovskite materials for high-performance solar cells. Nature 2015, 517, 476-480. [CrossRef] [PubMed]

4. Zhu, H.; Fu, Y.; Meng, F.; Wu, X.; Gong, Z.; Ding, Q.; Gustafsson, M.V.; Trinh, M.T.; Jin, S.; Zhu, X.Y. Lead halide perovskite nanowire lasers with low lasing thresholds and high quality factors. Nat. Mater. 2015, 14, 636-642. [CrossRef] [PubMed]

5. Sutherland, B.R.; Sargent, E.H. Perovskite photonic sources. Nat. Photonics 2016, 10, 295-302. [CrossRef]

6. Stranks, S.D.; Snaith, H.J. Metal-halide perovskites for photovoltaic and light-emitting devices. Nat. Nanotechnol. 2015, 10, 391-402. [CrossRef]

7. Huang, H.; Polavarapu, L.; Sichert, J.A.; Susha, A.S.; Urban, A.S.; Rogach, A.L. Colloidal lead halide perovskite nanocrystals: Synthesis, optical properties and applications. NPG Asia Mater. 2016, 8, e328. [CrossRef]

8. Protesescu, L.; Yakunin, S.; Bodnarchuk, M.I.; Krieg, F.; Caputo, R.; Hendon, C.H.; Yang, R.X.; Walsh, A.; Kovalenko, M.V. Nanocrystals of Cesium Lead Halide Perovskites ( $\mathrm{CsPb}_{3}, \mathrm{X}=\mathrm{Cl}, \mathrm{Br}$, and I): Novel Optoelectronic Materials Showing Bright Emission with Wide Color Gamut. Nano Lett. 2015, 15, 3692-3696. [CrossRef]

9. Huang, H.; Susha, A.S.; Kershaw, S.V.; Hung, T.F.; Rogach, A.L. Control of emission color of high quantum yield $\mathrm{CH}_{3} \mathrm{NH}_{3} \mathrm{PbBr}_{3}$ perovskite quantum dots by precipitation temperature. Adv. Sci. 2015, 2, 1500194. [CrossRef]

10. Cho, H.; Jeong, S.-H.; Park, M.-H.; Kim, Y.-H.; Wolf, C.; Lee, C.-L.; Heo, J.H.; Sadhanala, A.; Myoung, N.; Yoo, S.; et al. Overcoming the electroluminescence efficiency limitations of perovskite light-emitting diodes. Science 2015, 350, 1222-1225. [CrossRef]

11. Kim, Y.-H.; Cho, H.; Heo, J.H.; Kim, T.-S.; Myoung, N.; Lee, C.-L.; Im, S.H.; Lee, T.-W. Multicolored Organic/Inorganic Hybrid Perovskite Light-Emitting Diodes. Adv. Mater. 2015, 27, 1248-1254. [CrossRef] [PubMed]

12. Kim, Y.-H.; Cho, H.; Lee, T.-W. Metal halide perovskite light emitters. Proc. Natl. Acad. Sci. USA 2016, 113, 11694-11702. [CrossRef] [PubMed]

13. Wang, N.; Cheng, L.; Ge, R.; Zhang, S.; Miao, Y.; Zou, W.; Yi, C.; Sun, Y.; Cao, Y.; Yang, R.; et al. Perovskite light-emitting diodes based on solution-processed self-organized multiple quantum wells. Nat. Photonics 2016, 10, 699-704. [CrossRef]

14. Park, M.-H.; Jeong, S.-H.; Seo, H.-K.; Wolf, C.; Kim, Y.-H.; Kim, H.; Byun, J.; Kim, J.S.; Cho, H.; Lee, T.-W. Unravelling Additive-based Nanocrystal Pinning for High Efficiency Organic-Inorganic Halide Perovskite Light-Emitting Diodes. Nano Energy 2017, 42, 157-165. [CrossRef]

15. Zhou, Y.; Zhao, Y. Chemical stability and instability of inorganic halide perovskites. Energy Environ. Sci. 2019, 12, 1495. [CrossRef]

16. Tan, Z.K.; Moghaddam, R.S.; Lai, M.L.; Docampo, P.; Higler, R.; Deschler, F.; Price, M.; Sadhanala, A.L.; Pazos, M.; Credgington, D.; et al. Bright light-emitting diodes based on organometal halide perovskite. Nat. Nanotechnol. 2014, 9, 687-692. [CrossRef] [PubMed]

17. Lin, K.; Xing, J.; Quan, L.N.; Arquer, F.P.G.; Gong, X.; Lu, J.; Xie, L.; Zhao, W.; Zhang, D.; Yan, C.; et al. Perovskite light-emitting diodes with external quantum efficiency exceeding 20 per cent. Nature 2018, 562, 245-248. [CrossRef]

18. Cao, Y.; Wang, N.; Tian, H.; Guo, J.; Wei, Y.; Chen, H.; Miao, Y.; Zou, W.; Pan, K.; He, Y.; et al. Perovskite light-emitting diodes based on spontaneously formed submicrometre-scale structures. Nature 2018, 562, 249-253. [CrossRef]

19. Song, J.; Li, J.; Li, X.; Xu, L.; Dong, Y.; Zeng, H. Quantum Dot Light-Emitting Diodes Based on Inorganic Perovskite Cesium Lead Halides $\left(\mathrm{CsPbX}_{3}\right)$. Adv. Mater. 2016, 27, 7162-7167. [CrossRef]

20. Wei, S.; Yang, Y.; Kang, X.; Wang, L.; Huang, L.; Pan, D. Homogeneous Synthesis and Electroluminescence Device of Highly Luminescent CsPbBr $\backslash \mathbf{r}_{3} \backslash$ r Perovskite Nanocrystals. Inorg. Chem. 2017, 56, 2596-2601. [CrossRef] 
21. Yettapu, G.R.; Talukdar, D.; Sarkar, S.; Swarnkar, A.; Nag, A.; Ghosh, P.; Mandal, P. THz conductivity within colloidal $\mathrm{CsPbBr} \backslash \mathrm{r}_{3} \backslash \mathrm{r}$ perovskite nanocrystals: Remarkably high carrier mobilities and large diffusion lengths. Nano Lett. 2016, 16, 4838-4848. [CrossRef] [PubMed]

22. Swarnkar, A.; Marshall, A.R.; Sanehira, E.M.; Chernomordik, B.D.; Moore, D.T.; Christians, J.A.; Chakrabarti, T.; Luther, J.M. Quantum Dot-Induced Phase Stabilization Of $\Sigma$-Cspbi 3 Perovskite for High-Efficiency Photovoltaics. Science 2016, 354, 9295. [CrossRef] [PubMed]

23. Wang, Z.; Luo, Z.; Zhao, C.; Guo, Q.; Wang, Y.; Wang, F.; Bian, X.; Alsaedi, A.; Hayat, T.; Tan, Z. Efficient and Stable Pure Green All-Inorganic Perovskite $\mathrm{CsPbBr}_{3}$ Light-Emitting Diodes with a Solution-Processed NiOx Interlayer. J. Phys. Chem. C 2017, 121, 28132-28138. [CrossRef]

24. Jeong, B.; Han, H.; Choi, Y.J.; Cho, S.H.; Kim, E.H.; Lee, S.W.; Kim, J.S.; Park, C.; Kim, D.; Park, C. Inorganic $\mathrm{CsPbI}_{3}$ Perovskite Phase-Stabilized by Poly(ethylene oxide) for Red-Light-Emitting Diodes. Adv. Funct. Mater. 2018, 28, 1706401. [CrossRef]

25. Song, P.; Qiao, B.; Song, D.; Liang, Z.; Gao, D.; Cao, J.; Shen, Z.; Xu, Z.; Zhao, S. Colour- and structure-stable $\mathrm{CsPbBr} \mathrm{CsPb}_{2} \mathrm{r}_{5}$ compounded quantum dots with tuneable blue and green light emission. J. Alloy. Compd. 2018, 767, 98-105. [CrossRef]

26. Ng, Y.F.; Neo, W.J.; Jamaludin, N.F.; Yantara, N.; Mhaisalkar, S.; Mathews, N. Enhanced Coverage of All-Inorganic Perovskite $\mathrm{CsPbBr}_{3}$ through Sequential Deposition for Green Light-Emitting Diodes. Energy. Technol. 2017, 5, 1859-1865. [CrossRef]

27. Wu, Z.; Wei, J.; Sun, Y.; Wu, J.; Hou, Y.; Wang, P.; Wang, N.; Zhao, Z. Air-stable all-inorganic perovskite quantum dot inks for multicolor patterns and white LEDs. J. Mater. Sci. 2019, 54, 6917-6929.

28. Wu, H.; Zhang, Y.; Lu, M.; Zhang, X.; Sun, C.; Zhang, T.; Colvin, V.L.; Yu, W.W. Surface ligand modification of cesium lead bromide nanocrystals for improved light-emitting performance. Nanoscale 2018, 10, 4173-4178. [CrossRef]

29. Park, J.H.; Lee, A.-Y.; Yu, J.C.; Nam, Y.S.; Choi, Y.; Park, J.; Song, M.h. Surface Ligand Engineering for Efficient Perovskite Nanocrystal-Based Light-Emitting Diodes. ACS Appl. Mater. Interfaces 2019, 11, 8428-8435. [CrossRef]

30. Cheng, L.-P.; Huang, J.-S.; Shen, Y.; Li, G.-P.; Liu, X.-K.; Li, W.; Wang, Y.-H.; Li, Y.-Q.; Jiang, Y.; Gao, F.; et al. Efficient $\mathrm{CsPbr}_{3}$ Perovskite Light-Emitting Diodes Enabled by Synergetic Morphology Control. Adv. Opt. Mater. 2019, 7, 1801534. [CrossRef]

31. Wang, K.-H.; Zhu, B.-S.; Yao, J.-S.; Yao, H.-B. Chemical regulation of metal halide perovskite nanomaterials for efficient light-emitting diodes. Sci. Chin. Chem. 2018, 61, 1047-1061. [CrossRef]

32. Si, J.; Liu, Y.; He, Z.; Du, H.; Du, K.; Chen, D.; Li, J.; Xu, M.; Tian, H.; He, H.; et al. Efficient and High-Color-Purity Light-Emitting Diodes Based on In-Situ Grown Films of $\mathrm{CsPbX}_{3}(\mathrm{X}=\mathrm{Br}$, I) Nanoplates with Controlled Thicknesses. ACS Nano 2017, 11, 11100-11107. [CrossRef] [PubMed]

33. Sasaki, H.; Kamata, N.; Honda, Z.; Yasuda, T. Improved thermal stability of $\mathrm{CsPbBr}_{3}$ quantum dots by ligand exchange and their application to light-emitting diodes. Appl. Phys. Express 2019, 12, 035004. [CrossRef]

34. Song, L.; Guo, X.; Hu, Y.; Lv, Y.; Lin, J.; Fan, Y.; Zhang, N.; Liu, X. Improved performance of CsPbBr 3 perovskite light-emitting devices by both boundary and interface defects passivation. Nanoscale 2018, 10, 18315-18322. [CrossRef] [PubMed]

35. Wu, S.; Zhao, S.; Xu, Z.; Song, D.; Qiao, B.; Yue, H.; Yang, J.; Zheng, X.; Wei, P. Highly bright and stable all-inorganic perovskite light-emitting diodes with methoxypolyethylene glycols modified $\mathrm{CsPbBr}_{3}$ emission layer. Appl. Phys. Lett. 2018, 113, 213501. [CrossRef]

36. Chiba, T.; Hayashi, Y.; Ebe, H.; Hoshi, K.; Sato, J.; Sato, S.; Pu, Y.-J.; Ohisa, S.; Kido, J. Anion-exchange red perovskite quantum dots with ammonium iodine salts for highly efficient light-emitting devices. Nat. Photonics 2018, 12, 681-687. [CrossRef]

37. Yang, X.; Zhou, G.; Wong, W.-Y. Functionalization of Phosphorescent Emitters and Their Host Materials by Main-Group Elements for Phosphorescent Organic Light-Emitting Devices. Chem. Soc. Rev. 2015, 44, 8484-8575. [CrossRef]

38. Nishimoto, T.; Yasuda, T.; Lee, S.Y.; Kondo, R.; Adachi, C. A Six-carbazole-decorated Cyclophosphazene as a Host with High Triplet Energy to Realize Efficient Delayed-Fluorescence OLEDs. Mater. Horiz. 2014, 1, 264-269. [CrossRef] 
39. Liu, B.; Li, X.; Tao, H.; Zou, J.; Xu, M.; Wang, L.; Peng, J.; Cao, Y. Manipulation of Exciton Distribution for High-Performance Fluorescent/Phosphorescent Hybrid White Organic Light-Emitting Diodes. J. Mater. Chem. C 2017, 5, 7668-7683. [CrossRef]

40. Luo, D.; Xiao, P.; Liu, B. Doping-Free White Organic Light-Emitting Diodes. Chem. Rec. 2018, 18, 1-16. [CrossRef]

41. Fan, C.; Yang, C. Yellow/orange emissive heavy-metal complexes asphosphors in monochromatic and white organic light-emitting devices. Chem. Soc. Rev. 2014, 43, 6439-6469. [CrossRef] [PubMed]

42. Dai, X.L.; Zhang, Z.X.; Jin, Y.Z.; Niu, Y.; Cao, H.J.; Liang, X.Y.; Chen, L.W.; Wang, J.P.; Peng, X.G. Solution-Processed, High Performance Light-Emitting Diodes Based on Quantum Dots. Nature 2014, 515, 96-100. [CrossRef] [PubMed]

43. Mashford, B.S.; Stevenson, M.; Popovic, Z.; Hamilton, C.; Zhou, Z.; Breen, C.; Steckel, J.; Bulovic, V.; Bawendi, M.; Coe-Sullivan, S.; et al. High-efficiency quantum-dot light-emitting devices with enhanced charge injection. Nat. Photonics 2013, 7, 407-412. [CrossRef]

44. Shirasaki, Y.; Supran, G.J.; Bawendi, M.G.; Bulović, V. Emergence of colloidal quantum-dot light-emitting technologies. Nat. Photonics 2013, 7, 13-23. [CrossRef]

45. Yang, Y.X.; Zheng, Y.; Cao, W.R.; Titov, A.; Hyvonen, J.; Manders, J.R.; Xue, J.G.; Holloway, P.H.; Qian, L. High-Efficiency Light-Emitting Devices Based on Quantum Dots with Tailored Nanostructures. Nat. Photonics 2015, 9, 259-266. [CrossRef]

46. Shen, H.; Gao, Q.; Zhang, Y.; Lin, Y.; Lin, Q.L.; Li, Z.; Chen, L.; Zeng, Z.; Li, X.; Jia, Y.; et al. Visible quantum dot light-emitting diodes with simultaneous high brightness and efficiency. Nat. Photonics 2019, 13, $192-197$. [CrossRef]

47. Chiba, T.; Hoshi, K.; Pu, Y.-J.; Takeda, Y.; Hayashi, Y.; Ohisa, S.; Kawata, S.; Kido, J. High-Efficiency Perovskite Quantum-Dot Light-Emitting Devices by Effective Washing Process and Interfacial Energy Level Alignment. ACS Appl. Mater. Interfaces 2017, 9, 18054-18060. [CrossRef]

48. Hoshi, K.; Chiba, T.; Sato, J.; Hayashi, Y.; Takahashi, Y.; Ebe, H.; Ohisa, S.; Kido, J. Purification of Perovskite Quantum Dots Using Low-Dielectric-Constant Washing Solvent “Diglyme” for Highly Efficient Light-Emitting Devices. ACS Appl. Mater. Interfaces 2018, 10, 24607-24612. [CrossRef]

49. Li, J.; Xu, L.; Wang, T.; Song, J.; Chen, J.; Xue, J.; Dong, Y.; Cai, B.; Shan, G.; Han, B.; et al. 50-Fold EQE Improvement up to $6.27 \%$ of Solution-Processed All-Inorganic Perovskite $\mathrm{CsPbBr}_{3}$ QLEDs via Surface Ligand Density Control. Adv. Mater. 2017, 29, 1603885. [CrossRef]

50. Song, J.; Li, J.; Xu, L.; Li, J.; Zhang, F.; Han, B.; Shan, Q.; Zeng, H. Room-Temperature Triple-Ligand Surface Engineering Synergistically Boosts Ink Stability, Recombination Dynamics, and Charge Injection toward EQE-11.6\% Perovskite QLEDs. Adv. Mater. 2018, 30, 1800764. [CrossRef]

51. Song, J.; Fang, T.; Li, J.; Xu, L.; Zhang, F.; Han, B.; Shan, Q.; Zeng, H. Organic-Inorganic Hybrid Passivation Enables Perovskite QLEDs with an EQE of 16.48\%. Adv. Mater. 2018, 30, 1805409. [CrossRef] [PubMed]

52. Zhang, X.; Sun, C.; Zhang, Y.; Wu, H.; Ji, C.; Chuai, Y.; Wang, P.; Wen, S.; Zhang, C.; Yu, W.W. Bright Perovskite Nanocrystal Films for Efficient Light-Emitting Devices. J. Phys. Chem. Lett. 2016, 7, 4602-4610. [CrossRef] [PubMed]

53. Zhang, X.; Lu, M.; Zhang, Y.; Wu, H.; Shen, X.; Zhang, W.; Zheng, W.; Colvin, V.L.; Yu, W.W. PbS Capped

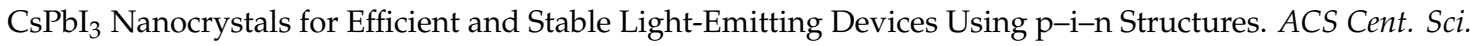
2018, 4, 1352-1359. [CrossRef] [PubMed]

54. Lu, M.; Wu, H.; Zhang, X.; Wang, H.; Hu, Y.; Colvin, V.L.; Zhang, Y.; Yu, W.W. Highly Flexible CsPbI 3 Perovskite Nanocrystal Light-Emitting Diodes. ChemNanoMat 2019, 5, 313-317. [CrossRef]

55. Pan, J.; Quan, L.N.; Zhao, Y.; Peng, W.; Murali, B.; Sarmah, S.P.; Yuan, M.; Sinatra, L.; Alyami, N.M.; Liu, J.; et al. Highly Efficient Perovskite-Quantum-Dot Light-Emitting Diodes by Surface Engineering. Adv. Mater. 2016, 28, 8718-8725. [CrossRef] [PubMed]

56. Lian, X.; Wang, X.; Ling, Y.; Lochner, E.; Tan, L.; Zhou, Y.; Ma, B.; Hanson, K.; Gao, H. Light Emitting Diodes Based on Inorganic Composite Halide Perovskites. Adv. Funct. Mater. 2019, 29, 1807345. [CrossRef]

57. Zhang, H.; Ye, F.; Li, W.; Yao, J.; Gurney, R.S.; Liu, D.; Xiong, C.; Wang, T. Bright perovskite light-emitting diodes with improved film morphology and reduced trap density via surface passivation using quaternary ammonium salts. Org. Electron. 2019, 67, 187-193. [CrossRef] 
58. Jia, Y.-L.; Wang, R.; Zhang, Y.; Ma, X.-J.; Yu, F.-X.; Xiong, Z.-Y.; Zhou, D.-Y.; Xiong, Z.-H.; Gao, C.-H. Large current efficiency enhancement in the $\mathrm{CsPBr}_{3}$ perovskite light emitting diodes assisted by an ultrathin buffer layer. J. Lumin. 2019, 209, 251-257. [CrossRef]

59. Meng, Y.; Ahmadi, M.; Wu, X.; Xu, T.; Xu, L.; Xiong, Z.; Chen, P. High performance and stable all-inorganic perovskite light emitting diodes by reducing luminescence quenching at PEDOT:PSS/Perovskites interface. Org. Electron. 2019, 64, 47-53. [CrossRef]

60. Yao, J.-S.; Ge, J.; Han, B.-N.; Wang, K.-H.; Yao, H.-B.; Yu, H.-L.; Li, J.-H.; Zhu, B.-S.; Song, J.-Z.; Chen, C.; et al. $\mathrm{Ce}^{3+}$-Doping to Modulate Photoluminescence Kinetics for Efficient $\mathrm{CsPbBr}_{3}$ Nanocrystals Based Light-Emitting Diodes. J. Am. Chem. Soc. 2018, 140, 3626-3634. [CrossRef]

61. Hames, B.C.; Sanchez, R.S.; Fakharuddin, A.; Mora-Sero, I. A Comparative Study of Light-Emitting Diodes Based on All-Inorganic Perovskite Nanoparticles $\left(\mathrm{CsPBr}_{3}\right)$ Synthesized at Room Temperature and by a Hot-Injection Method. Chempluschem 2018, 83, 294-299. [CrossRef]

62. Shen, X.; Zhang, Y.; Kershaw, S.V.; Li, T.; Wang, C.; Zhang, X.; Wang, W.; Li, D.; Wang, Y.; Lu, M.; et al. Zn-Alloyed $\mathrm{CsPbI}_{3}$ Nanocrystals for Highly Efficient Perovskite Light Emitting Devices. Nano. Lett. 2019, 19, 1552-1559. [CrossRef] [PubMed]

63. Cho, H.; Wolf, C.; Kim, J.S.; Yun, H.J.; Bae, S.S.; Kim, H.; Heo, J.-M.; Ahn, S.; Lee, T.-W. High-Efficiency Solution-Processed Inorganic Metal Halide Perovskite Light-Emitting Diodes. Adv. Mater. 2017, 29, 1700579. [CrossRef] [PubMed]

64. Zhang, X.; Wang, W.; Xu, B.; Liu, S.; Dai, H.; Bian, D.; Chen, S.; Wang, K.; Sun, X.W. Thin film perovskite light-emitting diode based on $\mathrm{CsPBr}_{3}$ powders and interfacial engineering. Nano Energy 2017, 37, 40-45. [CrossRef]

65. Le, Q.V.; Kim, J.B.; Kim, S.Y.; Lee, B.; Lee, D.R. Structural Investigation of Cesium Lead Halide Perovskites for High-Efficiency Quantum Dot Light-Emitting Diodes. J. Phys. Chem. Lett. 2017, 8, 4140-4147. [CrossRef]

66. Zhang, X.; Xu, B.; Wang, W.; Liu, S.; Zheng, Y.; Chen, S.; Wang, K.; Sun, X.W. Plasmonic Perovskite Light-Emitting Diodes Based on the Ag-CsPbBr 3 System. ACS Appl. Mater. Interfaces 2017, 9, 4926-4931. [CrossRef]

67. Chen, Y.; Zhao, F.; Zhao, Y.; Chen, J.; Ma, D. Ultra-simple hybrid white organic light-emitting diodes with high efficiency and CRI trade-off: Fabrication and emission-mechanism analysis. Org. Electron. 2012, 13, 2807-2815. [CrossRef]

68. Schwartz, G.; Fehse, K.; Pfeiffer, M.; Walzer, K.; Leo, K. Highly efficient white organic light emitting diodes comprising an interlayer to separate fluorescent and phosphorescent regions. Appl. Phys. Lett. 2006, 89, 083509. [CrossRef]

69. Jiang, C.; Zhong, Z.; Liu, B.; He, Z.; Zou, J.; Wang, L.; Wang, J.; Peng, J.B.; Cao, Y. Coffee-Ring-Free Quantum Dot Thin Film Using Inkjet Printing from a Mixed-Solvent System on Modified ZnO Transport Layer for Light-Emitting Devices. ACS Appl. Mater. Interfaces 2016, 8, 26162-26168. [CrossRef]

70. Liu, B.; Xu, Z.P.; Zou, J.H.; Tao, H.; Xu, M.; Gao, D.Y.; Lan, L.F.; Wang, L.; Ning, H.L.; Peng, J.B. High-performance hybrid white organic light-emitting diodes employing p-type interlayers. J. Ind. Eng. Chem. 2015, 27, 240-244. [CrossRef]

71. Luo, D.X.; Yang, Y.F.; Xiao, Y.; Zhao, Y.; Yang, Y.B.; Liu, B.Q. Regulating Charge and Exciton Distribution in High-Performance Hybrid White Organic Light-Emitting Diodes with n-Type Interlayer Switch. Nano-Micro Lett. 2017, 9, 37. [CrossRef] [PubMed]

72. Zhang, X.; Lin, H.; Huang, H.; Reckmeier, C.; Zhang, Y.; Choy, W.C.H.; Rogach, A.L. Enhancing the Brightness of Cesium Lead Halide Perovskite Nanocrystal Based Green Light-Emitting Devices through the Interface Engineering with Perfluorinated Ionomer. Nano Lett. 2016, 16, 1415-1420. [CrossRef] [PubMed]

73. Pu, Y.J.; Chiba, T.; Ideta, K.; Takahashi, S.; Aizawa, N.; Hikichi, T.; Kido, J. Fabrication of Organic Light-Emitting Devices Comprising Stacked Light-Emitting Units by Solution-Based Processes. Adv. Mater. 2015, 27, 1327-1332. [CrossRef] [PubMed]

74. Liu, B.; Wang, L.; Gao, D.Y.; Xu, M.; Zhu, X.H.; Zou, J.H.; Lan, L.F.; Ning, H.L.; Peng, J.B.; Cao, Y. Harnessing charge and exciton distribution towards extremely high performance: The critical role of guests in single-emitting-layer white OLEDs. Mater. Horiz. 2015, 2, 536-544. [CrossRef]

75. Zhao, Y.; Zhu, L.; Chen, J.; Ma, D. Improving Color Stability of Blue/Orange Complementary White OLEDs by Using Single-Host Double-Emissive Layer Structure: Comprehensive Experimental Investigation into the Device Working Mechanism. Org. Electron. 2012, 13, 1340-1348. [CrossRef] 
76. Jiang, C.; Liu, H.; Liu, B.; Zhong, Z.; Zou, J.; Wang, J.; Wang, L.; Peng, J.; Cao, Y. Improved performance of inverted quantum dots light emitting devices by introducing double hole transport layers. Org. Electron. 2016, 31, 82-89. [CrossRef]

77. Xiao, P.; Huang, J.; Yan, D.; Luo, D.; Yuan, J.; Liu, B.; Liang, D. Emergence of Nanoplatelet Light-Emitting Diodes. Materials 2018, 11, 1376. [CrossRef] [PubMed]

78. Moller, C.K. Crystal Structure and Photoconductivity of Casium Plumbohalides. Nature 1958, $182,1436$. [CrossRef]

79. Li, X.; Wu, Y.; Zhang, S.; Cai, B.; Gu, Y.; Song, J.; Zeng, H. CsPbX 3 Quantum Dots for Lighting and Displays: Room-Temperature Synthesis, Photoluminescence Superiorities, Underlying Origins and White Light-Emitting Diodes. Adv. Funct. Mater. 2016, 26, 2435-2445. [CrossRef]

80. Musselman, D.; Di, K.; Sadhanala, G.; Li, A.; Levskaya, Y.; Song, Q.; Tan, Z.; Lai, M.; Driscoll, J.; Greenham, N.; et al. Size-dependent photon emission from organometal halide perovskite nanocrystals embedded in an organic matrix. Nano. Lett. 2015, 6, 446-450.

81. Le, Q.V.; Park, M.; Sohn, W.; Jang, H.W.; Kim, S.Y. Investigation of Energy Levels and Crystal Structures of Cesium Lead Halides and Their Application in Full-Color Light-Emitting Diodes. Adv. Electron. Mater. 2017, 3, 1600448.

82. Du, X.; Wu, G.; Cheng, J.; Dang, H.; Ma, K.; Zhang, Y.-W.; Tan, P.-F.; Chen, S. High-quality CsPbBr 3 perovskite nanocrystals for quantum dot light-emitting diodes. RSC Adv. 2017, 7, 10391-10396. [CrossRef]

83. Butkus, J.; Vashishtha, P.; Chen, K.; Gallaher, J.K.; Prasad, S.K.K.; Metin, D.Z.; Laufersky, G.; Gaston, N.; Halpert, J.E.; Hodgkiss, J.M. The Evolution of Quantum Confinement in $\mathrm{CsPbBr}_{3}$ Perovskite Nanocrystals. Chem. Mater. 2017, 29, 3644-3652. [CrossRef]

84. Wu, C.; Zou, Y.; Wu, T.; Ban, M.; Pecunia, V.; Han, Y.; Liu, Q.; Song, T.; Duhm, S.; Sun, B. Improved Performance and Stability of All-Inorganic Perovskite Light-Emitting Diodes by Antisolvent Vapor Treatment. Adv. Funct. Mater. 2017, 27, 1700338. [CrossRef]

85. Wang, L.; Liu, B.; Zhao, X.; Demir, H.V.; Gu, H.; Sun, H. Solvent-Assisted Surface Engineering for High Performance All-Inorganic Perovskite Nanocrystals Light-Emitting Diodes. ACS Appl. Mater. Interfaces 2018, 10, 19828-19835. [CrossRef] [PubMed]

86. Chen, Z.; Nadal, B.; Mahler, B.; Aubin, H.; Dubertret, B. Quasi-2D Colloidal Semiconductor Nanoplatelets for Narrow Electroluminescence. Adv. Funct. Mater. 2014, 24, 295-302. [CrossRef]

87. Liu, B.; Delikanli, S.; Gao, Y.; Gungor, K.; Demir, H.V. Nanocrystal light-emitting diodes based on type II nanoplatelets. Nano Energy 2018, 47, 115-122. [CrossRef]

88. Huang, H.; Lin, H.; Kershaw, S.V.; Susha, A.S.; Choy, W.C.H.; Rogach, A.L. Polyhedral Oligomeric Silsesquioxane Enhances the Brightness of Perovskite Nanocrystal-Based Green Light-Emitting Devices. J. Phys. Chem. Lett. 2016, 7, 4398-4404. [CrossRef]

89. Zhang, X.; Xu, B.; Zhang, J.; Gao, Y.; Zheng, Y.; Wang, K.; Sun, X.W. All-Inorganic Perovskite Nanocrystals for High-Efficiency Light Emitting Diodes: Dual-Phase $\mathrm{CsPbr}_{3}-\mathrm{CsPb}_{2} \mathrm{Br}_{5}$ Composites. Adv. Funct. Mater. 2016, 26, 4595-4600. [CrossRef]

90. Pan, A.; He, B.; Fan, X.; Liu, Z.; Urban, J.J.; Alivisatos, A.P.; He, L.; Liu, Y. Insight into the Ligand-Mediated Synthesis of Colloidal CsPbBr $\backslash \mathrm{r}_{3} \backslash \mathbf{r}$ Perovskite Nanocrystals: The Role of Organic Acid, Base and Cs Precursors. ACS Nano 2016, 10, 7943-7954. [CrossRef]

91. Yao, E.-P.; Yang, Z.; Meng, L.; Sun, P.; Dong, S.; Yang, Y.; Yang, Y. High-Brightness Blue and White LEDs based on Inorganic Perovskite Nanocrystals and their Composites. Adv. Mater. 2017, 29, 1606859. [CrossRef] [PubMed]

92. Nedelcu, G.; Protesescu, L.; Yakunin, S.; Bodnarchuk, M.I.; Krieg, F.; Caputo, R.; Hendon, C.H.; Yang, R.X.; Walsh, A.; Kovalenko, M.V. Fast Anion-Exchange in Highly Luminescent Nanocrystals of Cesium Lead Halide Perovskites $\left(\mathrm{CsPbX}_{3}, \mathrm{X}=\mathrm{Cl}, \mathrm{Br}, \mathrm{I}\right)$. Nano Lett. 2015, 15, 5635-5640. [CrossRef] [PubMed]

93. Yantara, N.; Bhaumik, S.; Yan, F.; Sabba, D.; Dewi, H.A.; Mathews, N.; Boix, P.P.; Demir, H.V.; Mhaisalkar, S. Inorganic Halide Perovskites for Efficient Light-Emitting Diodes. J. Phys. Chem. Lett. 2015, 6, 4360-4364. [CrossRef] [PubMed]

94. Hu, Y.; Wang, Q.; Shi, Y.-L.; Li, M.; Zhang, L.; Wang, Z.-K.; Liao, L.-S. Vacuum-Evaporated All-Inorganic Cesium Lead Bromine Perovskites for High-Performance Light-Emitting Diodes. J. Mater. Chem. C 2017, 5 , 8144-8149. [CrossRef] 
95. Zhang, F.; Song, J.; Han, B.; Fang, T.; Li, J.; Zeng, H. High-Effciency Pure-Color Inorganic Halide Perovskite Emitters for Ultrahigh-Defnition Displays: Progressfor Backlighting Displays and Electrically Driven Devices. Small Methods 2018, 2, 1700382. [CrossRef]

96. Yang, X.; Zhang, X.; Deng, J.; Chu, Z.; Jiang, Q.; Meng, J.; Wang, P.; Zhang, L.; Yin, Z.; You, J. Efficient green light-emitting diodes based on quasi-two-dimensional composition and phase engineered perovskite with surface passivation. Nat. Commun. 2018, 9, 570. [CrossRef] [PubMed]

97. Ling, Y.; Tian, Y.; Wang, X.; Wang, J.C.; Knox, J.M.; Perez-Orive, F.; Du, Y.; Tan, L.; Hanson, K.; Ma, B.; et al. Enhanced Optical and Electrical Properties of Polymer-Assisted All-Inorganic Perovskites for Light-Emitting Diodes. Adv. Mater. 2016, 28, 8983-8989. [CrossRef] [PubMed]

98. Li, G.; Rivarola, F.W.R.; Davis, N.J.L.K.; Bai, S.; Jellicoe, T.C.; de la Pena, F.; Hou, S.; Ducati, C.; Gao, F.; Friend, R.H.; et al. Highly Efficient Perovskite Nanocrystal Light-Emitting Diodes Enabled by a Universal Crosslinking Method. Adv. Mater. 2016, 28, 3528-3534. [CrossRef]

99. Gangishetty, M.K.; Hou, S.; Quan, Q.; Congreve, D.N. Blue Perovskite LEDs: Reducing Architecture Limitations for Efficient Blue Perovskite Light-Emitting Diodes. Adv. Mater. 2018, 30, 1706226. [CrossRef]

100. Liu, B.; Gao, D.; Wang, J.; Wang, X.; Wang, L.; Zou, J.; Ning, H.; Peng, J. Progress of White Organic Light-Emitting Diodes. Acta Phys. Chim. Sin. 2015, 31, 1823-1852.

101. Rao, M.V.M.; Su, Y.K.; Huang, T.S.; Chen, Y.C. White Organic Light Emitting Devices Based on Multiple Emissive Nanolayers. Nano-Micro Lett. 2010, 2, 242-246.

102. Zhang, L.; Li, X.-L.; Luo, D.; Xiao, P.; Xiao, W.; Song, Y.; Ang, Q.; Liu, B. Strategies to Achieve High-Performance White Organic Light-Emitting Diodes. Materials 2017, 10, 1378. [CrossRef] [PubMed]

103. Kido, J.; Hongawa, K.; Okuyama, K.; Nagai, K. White Light-Emitting Organic Electroluminescent Devices Using The Poly ( $N$-vinylcarbazole) Emitter Layer Doped with Three Fluorescent Dyes. Appl. Phys. Lett. 1994, 64, 815. [CrossRef]

104. Al-Asbahi, B.A. Influence of $\mathrm{SiO}_{2} / \mathrm{TiO}_{2}$ Nanocomposite on the Optoelectronic Properties of PFO/MEH-PPV-Based OLED Devices. Polymers 2018, 10, 800. [CrossRef] [PubMed]

105. Luo, D.X.; Yang, Y.B.; Huang, L.; Liu, B.; Zhao, Y. High-performance hybrid white organic light-emitting diodes exploiting blue thermally activated delayed fluorescent dyes. Dyest. Pigment. 2017, 147, 83-89. [CrossRef]

106. Xiang, C.; Koo, W.; So, F.; Sasabe, H.; Kido, J. A Systematic Study on Efficiency Enhancements in Phosphorescent Green, Red and Blue Microcavity Organic Light Emitting Devices. Light: Sci. Appl. 2013, 2, e74. [CrossRef]

107. Xiao, P.; Dong, T.; Xie, J.; Luo, D.; Yuan, J.; Liu, B. Emergence of White Organic Light-Emitting Diodes Based on Thermally Activated Delayed Fluorescence. Appl. Sci. 2018, 8, 299. [CrossRef]

108. Hong, T.; Gao, D.; Liu, B.; Wang, L.; Zou, J.; Xu, M.; Peng, J. Enhancement of Tandem Organic Light-Emitting Diode Performance by Inserting An Ultra-Thin Ag Layer in Charge Generation Layer. Acta Phys. Sin. 2017, 1, 017302.

109. Rastogi, P.; Palazon, F.; Prato, M.; Stasio, F.D.; Krahne, R. Enhancing the Performance of CdSe/CdS Dot-in-Rod Light-Emitting Diodes via Surface Ligand Modification. ACS Appl. Mater. Interfaces 2018, 10, 5665-5672. [CrossRef]

110. Yang, D.; Zou, Y.; Li, P.; Liu, Q.; Wu, L.; Hu, H.; Xu, Y.; Sun, B.; Zhang, Q.; Lee, S.-T. Large-Scale Synthesis of Ultrathin Cesium Lead Bromide Perovskite Nanoplates with Precisely Tunable Dimensions and Their Application in Blue Light-Emitting Diodes. Nano Energy 2018, 47, 235-242. [CrossRef]

111. Wu, Y.; Wei, C.; Li, X.; Li, Y.; Qiu, S.; Shen, W.; Cai, B.; Sun, Z.; Yang, D.; Deng, Z.; et al. In Situ Passivation of $\mathrm{PbBr}_{6}{ }^{4-}$ Octahedra toward Blue Luminescent $\mathrm{CsPbBr}_{3}$ Nanoplatelets with Near $100 \%$ Absolute Quantum Yield. ACS Energy Lett. 2018, 3, 2030-2037. [CrossRef]

112. Sun, J.; Yang, J.; Lee, J.I.; Cho, J.H.; Kang, M.S. Lead-Free Perovskite Nanocrystals for Light-Emitting Devices. J. Phys. Chem. Lett. 2018, 9, 1573-1583. [CrossRef] [PubMed]

113. Kumawat, N.K.; Swarnkar, A.; Nag, A.; Kabra, D. Ligand Engineering to Improve the Luminance Efficiency of $\mathrm{CsPbBr}_{3}$ Nanocrystal Based Light-Emitting Diodes. J. Phys. Chem. C 2018, 122, 13767-13772. [CrossRef]

114. Jin, F.; Zhao, B.; Chu, B.; Zhao, H.; Su, Z.; Li, W.; Zhu, F. Morphology control towards bright and stable inorganic halide perovskite light-emitting diodes. J. Phys. Chem. C 2018, 6, 1573-1578. [CrossRef]

115. Kim, B.S.; Lee, J.Y. Engineering of Mixed Host for High External Quantum Efficiency above $25 \%$ in Green Thermally Activated Delayed Fluorescence Device. Adv. Funct. Mater. 2015, 24, 3970-3977. [CrossRef] 
116. Wang, M.; Hill, I.G. Fluorinated alkyl phosphonic acid SAMs replace PEDOT:PSS in polymer semiconductor devices. Org. Electron. 2012, 13, 498-505. [CrossRef]

117. Liu, B.; Wang, L.; Xu, M.; Tao, H.; Zou, J.H.; Gao, D.Y.; Lan, L.F.; Ning, H.L.; Peng, J.B.; Cao, Y. Efficient Hybrid White Organic Light-emitting Diodes with Extremely Long Lifetime: The Effect of n-type Interlayer. Sci. Rep. 2014, 4, 7198. [CrossRef] [PubMed]

118. Guo, J.J.; Li, X.L.; Nie, H.; Luo, W.W.; Gan, S.F.; Hu, S.M.; Hu, R.R.; Qin, A.J.; Zhao, Z.J.; Su, S.J.; et al. Achieving High-Performance Nondoped OLEDs with Extremely Small Efficiency Roll-Off by Combining Aggregation-Induced Emission and Thermally Activated Delayed Fluorescence. Adv. Funct. Mater. 2017, 27, 1606458. [CrossRef]

119. Sun, N.; Zhao, Y.B.; Zhao, F.C.; Chen, Y.H.; Yang, D.Z.; Chen, J.S.; Ma, D.G. A white organic light-emitting diode with ultra-high color rendering index, high efficiency, and extremely low efficiency roll-off. Appl. Phys. Lett. 2014, 105, 013303. [CrossRef]

120. Luo, D.X.; Xiao, Y.; Hao, M.M.; Zhao, Y.; Yang, Y.B.; Gao, Y.; Liu, B. Doping-free white organic light-emitting diodes without blue molecular emitter: An unexplored approach to achieve high performance via exciplex emission. Appl. Phys. Lett. 2017, 110, 061105. [CrossRef]

121. Luo, D.; Chen, Q.; Gao, Y.; Zhang, M.; Liu, B. Extremely Simplified, High-Performance and Doping-Free White Organic Light-Emitting Diodes Based on Single Thermally Activated Delayed Fluorescent Emitter. ACS Energy Lett. 2018, 3, 1531-1538. [CrossRef]

122. Liu, B.; Luo, D.X.; Zou, J.H.; Gao, D.Y.; Ning, H.L.; Wang, L.; Peng, J.B.; Cao, Y. A host-guest system comprising high guest concentration to achieve simplified and high-performance hybrid white organic light-emitting diodes. J. Mater. Chem. C 2015, 3, 6359-6366. [CrossRef]

123. Ying, L.; Ho, C.L.; Wu, H.; Cao, Y.; Wong, W.Y. White Polymer Light-Emitting Devices for Solid-State Lighting: Materials, Devices, and Recent Progress. Adv. Mater. 2014, 26, 2459-2473. [CrossRef] [PubMed]

124. Zou, J.; Wu, H.; Lam, C.S.; Wang, C.; Zhong, C.; Hu, S.; Ho, C.L.; Zhou, G.J.; Wu, H.; Choy, W.C.; et al. Simultaneous Optimization of Charge-Carrier Balance and Luminous Efficacy in Highly Efficient White Polymer Light-Emitting Devices. Adv. Mater. 2011, 23, 2976-2980. [CrossRef] [PubMed]

125. Liu, B.; Xu, M.; Tao, H.; Ying, L.; Zou, J.; Wu, H.; Peng, J. Highly Efficient Red Phosphorescent Organic Light-Emitting Diodes Based on Solution Processed Emissive Layer. J. Lumin. 2013, 142, 35-39. [CrossRef]

126. Mai, R.S.; Wu, X.Y.; Jiang, Y.; Meng, Y.Y.; Liu, B.Q.; Hu, X.W.; Roncali, J.; Zhou, G.F.; Liu, J.-M.; Kempa, K.; et al. An efficient multi-functional material based on polyether-substituted indolocarbazole for perovskite solar cells and solution-processed non-doped OLEDs. J. Mater. Chem. A 2019, 7, 1539-1547. [CrossRef]

127. Shen, P.Y.; Li, X.M.; Cao, F.; Ding, X.W.; Yang, X.Y. Highly efficient, all-solution-processed, flexible white quantum dot light-emitting diodes. J. Mater. Chem. C 2018, 6, 9642-9648. [CrossRef]

128. Zhu, L.P.; Zhao, Y.B.; Zhang, H.M.; Chen, J.S.; Ma, D.G. Using an ultra-thin non-doped orange emission layer to realize high efficiency white organic light-emitting diodes with low efficiency roll-off. J. Appl. Phys. 2014, 115, 244512. [CrossRef]

129. Liu, B.; Zou, J.H.; Zhou, Z.W.; Wang, L.; Xu, M.; Tao, H.; Gao, D.Y.; Lan, L.Y.; Ning, H.L.; Peng, J.B. Efficient single-emitting layer hybrid white organic light-emitting diodes with low efficiency roll-off, stable color and extremely high luminance. J. Ind. Eng. Chem. 2015, 30, 85-91. [CrossRef]

130. Wu, Z.B.; Sun, N.; Zhu, L.P.; Sun, H.D.; Wang, J.X.; Yang, D.Z.; Qiao, X.F.; Chen, J.S.; Alshehri, S.; Ahamad, T.; et al. Achieving Extreme Utilization of Excitons by an Efficient Sandwich-Type Emissive Layer Architecture for Reduced Efficiency Roll-Off and Improved Operational Stability in Organic Light-Emitting Diodes. ACS Appl. Mater. Interfaces 2016, 8, 3150-3159. [CrossRef]

131. Sun, Y.R.; Giebink, N.C.; Kanno, H.; Ma, B.W.; Thompson, M.E.; Forrest, S.R. Management of Singlet and Triplet Excitons for Efficient White Organic Light-Emitting Devices. Nature 2006, 440, 908-912. [CrossRef] [PubMed]

132. Chen, B.; Liu, B.; Zeng, J.; Nie, H.; Xiong, Y.; Zou, J.; Ning, H.; Wang, Z.; Zhao, Z.; Tang, B.Z. Efficient Bipolar Blue AIEgens for High-Performance Nondoped Blue OLEDs and Hybrid White OLEDs. Adv. Funct. Mater. 2018, 28, 1803369. [CrossRef]

133. Liu, B.; Xu, M.; Wang, L.; Zou, J.H.; Tao, H.; Su, Y.J.; Gao, D.Y.; Ning, H.L.; Lan, L.F.; Peng, J.B. Regulating charges and excitons in simplified hybrid white organic light-emitting diodes: The key role of concentration in single dopant host-guest systems. Org. Electron. 2014, 15, 2616-2623. [CrossRef] 
134. Zhao, F.C.; Zhang, Z.Q.; Liu, Y.P.; Dai, Y.F.; Chen, J.S.; Ma, D. A Hybrid White Organic Light-Emitting Diode with Stable Color and Reduced Efficiency Roll-Off by Using a Bipolar Charge Carrier Switch. Org. Electron. 2012, 13, 1049-1055. [CrossRef]

135. Chen, Y.-H.; Ma, D.-G.; Sun, H.-D.; Chen, J.-S.; Guo, Q.-X.; Wang, Q.; Zhao, Y.-B. Organic Semiconductor Heterojunctions: Electrode-Independent Charge Injectors for High-Performance Organic Light-Emitting Diodes. Light: Sci. Appl. 2016, 5, e16042. [CrossRef] [PubMed]

136. Xiao, P.; Huang, J.; Yu, Y.; Liu, B. Recent Developments in Tandem White Organic Light-Emitting Diodes. Molecules 2019, 24, 151. [CrossRef] [PubMed]

137. Liu, B.; Xu, M.; Wang, L.; Tao, H.; Su, Y.; Gao, D.; Zou, J.; Lan, L.; Peng, J. Comprehensive Study on the Electron Transport Layer in Blue Flourescent Organic Light-Emitting Diodes. ECS J. Solid State Sci. Technol. 2015, 2, R258-R261. [CrossRef]

138. Krotkus, S.; Kasemann, D.; Lenk, S.; Leo, K.; Reineke, S. Adjustable White-Light Emission From a Photo-Structured Micro-OLED Array. Light: Sci. Appl. 2016, 5, e16121. [CrossRef]

139. Zhao, B.; Zhang, T.Y.; Li, W.L.; Su, Z.S.; Chu, B.; Yan, X.W.; Jin, F.M.; Gao, Y.; Wu, H. Organic Electronics Highly efficient and color stable single-emitting-layer fluorescent WOLEDs with delayed fluorescent host. Org. Electron. 2015, 23, 208-212. [CrossRef]

140. Liu, B.; Wang, L.; Zou, J.H.; Tao, H.; Su, Y.J.; Gao, D.Y.; Xu, M.; Lan, L.F.; Peng, J.B. Investigation on spacers and structures: A simple but effective approach toward high-performance hybrid white organic light emitting diodes. Synth. Met. 2013, 184, 5-9. [CrossRef]

141. Du, X.; Tao, S.; Huang, Y.; Yang, X.; Ding, X.; Zhang, X. Efficient Fluorescence/Phosphorescence White Organic Light-Emitting Diodes with Ultra High Color Stability and Mild Efficiency Roll-Off. Appl. Phys. Lett. 2015, 107, 183304. [CrossRef]

142. Luo, D.; Li, X.-L.; Zhao, Y.; Gao, Y.; Liu, B. High-Performance Blue Molecular Emitter-Free and Doping-Free Hybrid White Organic Light-Emitting Diodes: An Alternative Concept to Manipulate Charges and Excitons Based on Exciplex and Electroplex Emission. ACS Photonics 2017, 4, 1566-1575. [CrossRef]

143. Jou, J.-H.; Hsieh, C.-Y.; Tseng, J.-R.; Peng, S.-H.; Jou, Y.-C.; Hong, J.H.; Shen, S.-M.; Tang, M.-C.; Chen, P.-C.; Lin, C.-H. Candle Light-Style Organic Light-Emitting Diodes. Adv. Funct. Mater. 2013, 23, 2750-2757. [CrossRef]

144. Xiao, P.; Huang, J.; Yu, Y.; Yuan, J.; Luo, D.; Liu, B.; Liang, D. Recent Advances of Exciplex-Based White Organic Light-Emitting Diodes. Appl. Sci. 2018, 8, 1449. [CrossRef]

145. Liu, B.; Wang, L.; Xu, M.; Tao, H.; Xia, X.; Zou, J.; Su, Y.; Gao, D.; Lan, L.; Peng, J. Simultaneous Achievement of Low Efficiency Roll-Off and Stable Color in Highly Efficient Single-Emitting-Layer Phosphorescent White Organic Light-Emitting Diodes. J. Mater. Chem. C 2014, 2, 5870-5877. [CrossRef]

146. Schwartz, G.; Reineke, S.; Rosenow, T.C.; Walzer, K.; Leo, K. Triplet Harvesting in Hybrid White Organic Light-Emitting Diodes. Adv. Funct. Mater. 2009, 19, 1319-1333. [CrossRef]

147. Liu, B.; Nie, H.; Zhou, X.B.; Hu, S.B.; Luo, D.X.; Gao, D.Y.; Zou, J.H.; Xu, M.; Wang, L.; Zhao, Z.J.; et al. Manipulation of Charge and Exciton Distribution Based on Blue Aggregation-Induced Emission Fluorophors: A Novel Concept to Achieve High-Performance Hybrid White Organic Light-Emitting Diodes. Adv. Funct. Mater. 2016, 26, 776-783. [CrossRef]

148. Adachi, C.; Baldo, M.A.; Thompson, M.E.; Forrest, S.R. Nearly 100\% Internal Phosphorescence Efficiency in an Organic Light-Emitting Device. J. Appl. Phys. 2001, 90, 5048-5051. [CrossRef]

149. Kanno, H.; Holmes, R.J.; Sun, Y.; Kena, S.; Forrest, S.R. White Stacked Electrophosphorescent Organic Light-Emitting Devices Employing $\mathrm{MoO}_{3}$ as a Charge-Generation Layer. Adv. Mater. 2006, 18, 339-342. [CrossRef]

150. Cho, Y.J.; Yook, K.S.; Lee, J.Y. Cool and Warm Hybrid White Organic Light-Emitting Diode with Blue Delayed Fluorescent Emitter Both as Blue Emitter and Triplet Host. Sci. Rep. 2015, 5, 7859. [CrossRef]

151. Xiang, H.-Y.; Li, Y.-Q.; Meng, S.-S.; Lee, C.-S.; Chen, L.-S.; Tang, J.-X. Extremely Efficient Transparent Flexible Organic Light-Emitting Diodes with Nanostructured Composite Electrodes. Adv. Opt. Mater. 2018, 6, 1800831. [CrossRef]

152. Liu, B.; Xu, M.; Tao, H.; Su, Y.J.; Gao, D.Y.; Zou, J.H.; Lan, L.F.; Peng, J.B. The effect of spacer in hybrid white organic light emitting diodes. Chin. Sci. Bull. 2014, 59, 3090-3097. [CrossRef] 
153. Chen, Y.H.; Chen, J.S.; Ma, D.G.; Yan, D.H.; Wang, L.X.; Zhu, F.R. High Power Efficiency Tandem Organic Light-Emitting Diodes Based on Bulk Heterojunction Organic Bipolar Charge Generatio Layer. Appl. Phys. Lett. 2011, 98, 243309. [CrossRef]

154. Zhou, J.; Zou, J.; Dai, C.; Zhang, Y.; Luo, X.; Liu, B. High-Efficiency and High-Luminance Three-Color White Organic Light-Emitting Diodes with Low Efficiency Roll-Off. ECS J. Solid State Sci. Technol. 2018, 7, R99-R103. [CrossRef]

155. Poloek, A.; Chen, C.-T.; Chen, C.-T. High performance hybrid white and multi-colour electroluminescence from a new host material for a heteroleptic naphthyridinolate platinum complex dopant. J. Mater. Chem. C 2014, 2, 1376-1380. [CrossRef]

156. Sun, N.; Wang, Q.; Zhao, Y.B.; Yang, D.Z.; Zhao, F.C.; Chen, J.S.; Ma, D.G. A hybrid white organic light-emitting diode with above $20 \%$ external quantum efficiency and extremely low efficiency roll-off. J. Mater. Chem. C 2014, 2, 7494-7504. [CrossRef]

157. Wu, Z.; Yu, L.; Zhao, F.; Qiao, X.; Chen, J.; Ni, F.; Yang, C.; Ahamad, T.; Alshehri, S.M.; Ma, D. Precise Exciton Allocation for Highly Effcient White Organic Light-Emitting Diodes with Low Effciency Roll-Off Based on Blue Thermally Activated Delayed Fluorescent Exciplex Emission. Adv. Opt. Mater. 2017, 5, 1700415. [CrossRef]

158. Liu, B.; Tao, H.; Su, Y.J.; Gao, D.Y.; Lan, L.F.; Zou, J.H.; Peng, J.B. Color-stable, reduced efficiency roll-off hybrid white organic light emitting diodes with ultra high brightness. Chin. Phys. B 2013, 22, 077303. [CrossRef]

159. Liu, B.; Tao, H.; Wang, L.; Gao, D.Y.; Liu, W.C.; Zou, J.H.; Xu, M.; Ning, H.L.; Peng, J.B.; Cao, Y. High-performance doping-free hybrid white organic light-emitting diodes: The exploitation of ultrathin emitting nanolayers (<1 nm). Nano Energy 2016, 26, 26-36.

160. Schwartz, G.; Ke, T.-H.; Wu, C.-C.; Walzer, K.; Leo, K. Balanced ambipolar charge carrier mobility in mixed layers for application in hybrid white organic light-emitting diodes. Appl. Phys. Lett. 2008, 93, 073304. [CrossRef]

161. Byun, J.; Cho, H.; Wolf, C.; Jang, M.; Sadhanala, A.; Friend, R.H.; Yang, H.; Lee, T.-W. Efficient Visible Quasi-2D Perovskite Light-Emitting Diodes. Adv. Mater. 2016, 28, 7515-7520. [CrossRef] [PubMed]

162. Li, X.L.; Ouyang, X.H.; Liu, M.; Ge, Z.Y.; Peng, J.B.; Cao, Y.; Su, S.J. Highly efficient single-and multi-emission-layer fluorescent/phosphorescent hybrid white organic light-emitting diodes with 20\% external quantum efficiency. J. Mater. Chem. C 2015, 3, 9233-9239. [CrossRef]

163. Liu, B.; Wang, L.; Gao, D.Y.; Zou, J.H.; Ning, H.L.; Peng, J.B.; Cao, Y. Extremely high-efficiency and ultrasimplified hybrid white organic light-emitting diodes exploiting double multifunctional blue emitting layers. Light: Sci. Appl. 2016, 5, e16137. [CrossRef] [PubMed]

164. Reineke, S.; Lindner, F.; Schwartz, G.; Seidler, N.; Walzer, K.; Lüssem, B.; Leo, K. White organic light-emitting diodes with fluorescent tube efficiency. Nature 2009, 459, 234. [CrossRef] [PubMed]

165. Schwartz, G.; Pfeiffer, M.; Reineke, S.; Walzer, K.; Leo, K. Harvesting Triplet Excitons from Fluorescent Blue Emitters in White Organic Light-Emitting Diodes. Adv. Mater. 2007, 19, 3672-3676. [CrossRef]

166. Ye, J.; Zheng, C.-J.; Ou, X.-M.; Zhang, X.-H.; Fung, M.-K.; Lee, C.-S. Management of Singlet and Triplet Excitons in a Single Emission Layer: A Simple Approach for a High-Efficiency Fluorescence/Phosphorescence Hybrid White Organic Light-Emitting Device. Adv. Mater. 2012, 24, 3410-3414. [CrossRef] [PubMed]

167. Liu, B.; Xu, M.; Wang, L.; Yan, X.; Tao, H.; Su, Y.; Gao, D.; Lan, L.; Zou, J.; Peng, J. Investigation and Optimization of Each Organic Layer: A Simple But Effective Approach Towards Achieving High-Efficiency Hybrid White Organic Light-Emitting Diodes. Org. Electron. 2014, 15, 926-936. [CrossRef]

168. Liu, B.; Zou, J.H.; Su, Y.J.; Gao, D.Y.; Lan, L.F.; Tao, H.; Peng, J.B. Hybrid white organic light emitting diodes with low efficiency roll-off, stable color and extreme brightness. J. Lumin. 2014, 151, 161-164. [CrossRef]

169. Wu, J.B.; Agrawal, M.; Becerril, H.A.; Bao, Z.A.; Liu, Z.F.; Chen, Y.S.; Peumans, P. Organic light-emitting diodes on solution processed graphene transparent electrodes. ACS Nano 2010, 4, 43-48. [CrossRef]

170. Sun, T.; Wang, Z.L.; Shi, Z.J.; Ran, G.Z.; Xu, W.J.; Wang, Z.Y.; Li, Y.Z.; Dai, L.; Qin, G.G. Multilayered graphene used as anode of organic light emitting devices. Appl. Phys. Lett. 2010, 96, 133301. [CrossRef]

171. Liu, B.; Xu, M.; Wang, L.; Tao, H.; Su, Y.J.; Gao, D.Y.; Lan, L.F.; Zou, J.H.; Peng, J.B. Simplified hybrid white organic light-emitting diodes with efficiency/efficiency roll-off/color rendering index/color-stability trade-off. Phys. Status Solidi RRL 2014, 8, 719-723. [CrossRef] 
172. Liu, B.; Nie, H.; Lin, G.; Hu, S.; Gao, D.; Zou, J.; Xu, M.; Wang, L.; Zhao, Z.; Ning, H.; et al. High-Performance Doping-Free Hybrid White OLEDs Based on Blue Aggregation-Induced Emission Luminogens. ACS Appl. Mater. Interfaces 2017, 9, 34162-34171. [CrossRef] [PubMed]

173. Jou, J.-H.; Shen, S.-M.; Lin, C.-R.; Wang, Y.-S.; Chou, Y.-C.; Chen, S.-Z.; Jou, Y.-C. Efficient Very-High Color Rendering index Organic Light-Emitting Diode. Org. Electron. 2011, 12, 865-868. [CrossRef]

174. Quan, L.N.; Rand, B.P.; Friend, H.; Mhaisalkar, S.G.; Lee, T.-W.; Sargent, E.H. Perovskites for Next-Generation Optical Sources. Chem. Rev. 2019, 119, 7444-7477. [CrossRef] [PubMed]

175. Fakharuddin, A.; Shabbir, U.; Qiu, W.; Iqbal, T.; Sultan, M.; Heremans, P.; Schmidt-Mende, L. Inorganic and Layered Perovskites for Optoelectronic Devices. Adv. Mater. 2019, 1807095. [CrossRef] [PubMed]

176. Wei, Y.; Cheng, Z.; Lin, J. An overview on enhancing the stability of lead halide perovskite quantum dots and their applications in phosphor-converted LEDs. Chem. Soc. Rev. 2019, 48, 310-350. [CrossRef] [PubMed]

177. Kulkarni, S.A.; Mhaisalkar, S.G.; Mathews, N.; Boix, P.P. Perovskite Nanoparticles: Synthesis, Properties, and Novel Applications in Photovoltaics and LEDs. Small Methods 2019, 3, 1800231. [CrossRef]

178. Jurow, M.J.; Morgenstern, T.; Eisler, C.; Kang, J.; Penzo, E.; Do, M.; Engelmayer, M.; Osowiecki, W.T.; Bekenstein, Y.; Tassone, C.; et al. Manipulating the Transition Dipole Moment of $\mathrm{CsPbr}_{3}$ Perovskite Nanocrystals for Superior Optical Properties. Nano. Lett. 2019, 19, 2489-2496. [CrossRef]

179. You, J.-D.; Tseng, S.-R.; Meng, H.-F.; Yen, F.-W.; Lin, I.-F.; Horng, S.-F. All-solution-processed blue small molecular organic light-emitting diodes with multilayer device structure. Org. Electron. 2009, 10, 1610-1614. [CrossRef]

180. Zhang, M.; Hofle, S.; Czolk, J.; Mertens, A.; Colsmann, A. All-solution processed transparent organic light emitting diodes. Nanoscale 2015, 7, 20009-20014. [CrossRef]

181. Chen, J.; Zhao, D.; Li, C.; Xu, F.; Lei, W.; Sun, L.; Nathan, A.; Sun, X.W. All Solution-processed Stable White

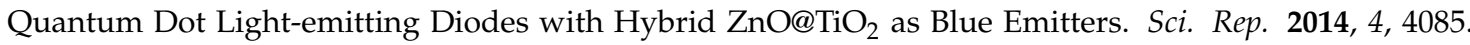
[CrossRef] [PubMed]

182. Castan, A.; Kim, H.-M.; Jang, J. All-solution-processed inverted quantum-dot light-emitting diodes. ACS Appl. Mater. Interfaces 2014, 6, 2508-2515. [CrossRef] [PubMed]

183. Kim, D.; Fu, Y.; Kim, S.; Lee, W.; Lee, K.-H.; Chung, H.K.; Lee, H.-J.; Yang, H.; Chae, H. Polyethylenimine Ethoxylated-Mediated All-Solution-Processed High-Performance Flexible Inverted Quantum Dot-LightEmitting Device. ACS Nano 2017, 11, 1982-1990. [CrossRef] [PubMed]

184. Duan, L.; Zhang, D.Q.; Wu, K.W.; Huang, X.Q.; Wang, L.D.; Qiu, Y. Controlling the Recombination Zone of White Organic Light-Emitting Diodes with Extremely Long Lifetimes. Adv. Funct. Mater. 2011, 21, 3540-3545. [CrossRef]

185. Jou, J.-H.; Wu, R.-Z.; Yu, H.-H.; Li, C.-J.; Jou, Y.-C.; Peng, S.-H.; Chen, Y.-L.; Chen, C.-T.; Shen, S.-M.; Joers, P.; et al. Artificial Dusk-Light Based on Organic Light Emitting Diodes. ACS Photonics 2014, 1, 27-31. [CrossRef]

186. Liu, B.; Xu, M.; Wang, L.; Tao, H.; Su, Y.; Gao, D.; Lan, L.; Zou, J.; Peng, J. Very-High Color Rendering Index Hybrid White Organic Light-Emitting Diodes with Double Emitting Nanolayers. Nano-Micro Lett. 2014, 6, 335-339. [CrossRef] [PubMed]

187. Liu, B.; Luo, D.; Gao, D.; Wang, X.; Xu, M.; Zou, J.; Ning, H.; Wang, L.; Peng, J.; Cao, Y. An ideal host-guest system to accomplish high-performance greenishyellow and hybrid white organic light-emitting diodes. Org. Electron. 2015, 27, 29-34. [CrossRef]

188. Jou, J.H.; Wu, M.H.; Shen, S.M.; Wang, H.C.; Chen, S.Z.; Chen, S.H.; Lin, C.R.; Hsieh, Y.L. Sunlight-Style Color-Temperature Tunable Organic Light-Emitting Diode. Appl. Phys. Lett. 2009, 95, 013307. [CrossRef]

189. Zhang, D.D.; Zhang, D.Q.; Duan, L. Exploiting p-Type Delayed Fluorescence in Hybrid White OLEDs: Breaking the Trade-off between High Device Efficiency and Long Lifetime. ACS Appl. Mater. Interfaces 2016, 8, 23197-23203. [CrossRef]

190. Zhang, T.; Zhao, B.; Chu, B.; Li, W.; Su, Z.; Yan, X.; Liu, C.; Wu, H.; Gao, Y.; Jin, F.; et al. Simple structured hybrid WOLEDs based on incomplete energy transfer mechanism: From blue exciplex to orange dopant. Sci. Rep. 2015, 5, 10234. [CrossRef]

191. Liu, B.; Xu, M.; Wang, L.; Su, Y.J.; Gao, D.Y.; Tao, H.; Lan, L.F.; Zou, J.H.; Peng, J.B. High-Performance Hybrid White Organic Light-Emitting Diodes Comprising Ultrathin Blue and Orange Emissive Layers. Appl. Phys. Express 2013, 6, 122101. [CrossRef] 
192. Zhang, D.D.; Duan, L.; Zhang, Y.G.; Cai, M.H.; Zhang, D.Q.; Qiu, Y. Highly efficient hybrid warm white organic light-emitting diodes using a blue thermally activated delayed fluorescence emitter: Exploiting the external heavy-atom effect. Light: Sci. Appl. 2015, 4, e232. [CrossRef]

193. Zhang, D.D.; Duan, L.; Li, Y.L.; Zhang, D.Q.; Qiu, Y. Highly efficient and color-stable hybrid warm white organic light-emitting diodes using a blue material with thermally activated delayed fluorescence. J. Mater. Chem. C 2014, 2, 8191-8197. [CrossRef]

194. Wu, Z.; Qi, W.; Ling, Y.; Chen, J.; Qiao, X.; Ahamad, T.; Alshehri, S.M.; Yang, C.; Ma, D. Managing excitons and charges for high-performance fluorescent white organic light-emitting diodes. ACS Appl. Mater. Interfaces 2016, 8, 28780-28788. [CrossRef] [PubMed]

195. Liu, B.; Lan, L.; Zou, J.; Peng, J. A novel organic light-emitting diode by utilizing double hole injection layer. Acta Phys. Sin. 2013, 62, 087302.

196. Son, Y.H.; Kim, Y.J.; Park, M.J.; Oh, H.Y.; Park, J.S.; Yang, J.H.; Suh, M.C.; Kwon, J.H. Small single-triplet energy gap bipolar host materials for phosphorescent blue and white organic light emitting diodes. J. Mater. Chem. C 2013, 1, 5008. [CrossRef]

197. Zhang, D.; Cai, M.H.; Zhang, Y.G.; Zhang, D.Q.; Duan, L. Sterically Shielded Blue Thermally Activated Delayed Fluorescence Emitters with Improved Efficiency and Stability. Mater. Horiz. 2016, 3, 145-151. [CrossRef]

198. Zhang, D.; Duan, L.; Li, C.; Li, Y.; Li, H.; Zhang, D.; Qiu, Y. High-Efficiency Fluorescent Organic Light-Emitting Devices Using Sensitizing Hosts with a Small Singlet-Triplet Exchange Energy. Adv. Mater. 2014, 26, 5050-5055. [CrossRef] [PubMed]

199. Kim, Y.-H.; Wof, C.; Kim, Y.-T.; Cho, H.; Kwon, W.; Do, S.; Sadhanala, A.; Park, C.G.; Rhee, S.-W.; Im, S.H.; et al. Highly efficient light-emitting diodes of colloidal metal-halide perovskite nanocrystals beyond quantum size. ACS Nano 2017, 11, 6586-6593. [CrossRef]

200. Seo, H.-K.; Kim, H.; Lee, J.; Park, M.-H.; Jeong, S.-H.; Kim, Y.-H.; Kwon, S.-J.; Han, T.-H.; Yoo, S.; Yoo, S.; et al. Efficient Flexible Organic/Inorganic Hybrid Perovskite Light-Emitting Diodes Based on Graphene Anode. Adv. Mater. 2017, 29, 1605587. [CrossRef]

201. Ricciardulli, A.G.; Yang, S.; Kotadiya, N.B.; Wetzelaer, G.-J.A.H.; Feng, X.; Blom, P.W.M. Improved Hole Injection into Perovskite Light-Emitting Diodes Using A Black Phosphorus Interlayer. Adv. Electron. Mater. 2019, 5, 1800687. [CrossRef]

202. Chiba, T.; Pu, Y.J.; Kido, J. Solution-Processed White Phosphorescent Tandem Organic Light-Emitting Devices. Adv. Mater. 2015, 27, 4681-4687. [CrossRef] [PubMed]

203. Shi, H.; Liu, C.C.; Jiang, Q.L.; Xu, J.K. Effective Approaches to Improve the Electrical Conductivity of PEDOT: PSS: A Review. Adv. Electron. Mater. 2015, 1, 1500017. [CrossRef]

204. Liu, G.H.; Zhou, X.; Chen, S.M. Very Bright and Efficient Microcavity Top-Emitting Quantum Dot Light-Emitting Diodes with Ag Electrodes. ACS Appl. Mater. Interfaces 2016, 8, 16768-16775. [CrossRef] [PubMed]

205. Zhao, B.; Zhang, T.; Chu, B.; Li, W.; Su, Z.; Luo, Y.; Li, R.; Yan, X.; Jin, F.; Gao, Y.; et al. Highly efficient tandem full exciplex orange and warm white OLEDs based on thermally activated delayed fluorescence mechanism. Org. Electron. 2015, 17, 15-21. [CrossRef]

206. Rajamalli, P.; Senthilkumar, N.; Gandeepan, P.; Huang, P.-Y.; Huang, M.-J.; Yang, C.-Y.; Chiu, M.-J.; Chu, L.-K.; Lin, H.-W.; Cheng, C.-H. A New Molecular Design Based on Thermally Activated Delayed Fluorescence for Highly Efficient Organic Light Emitting Diodes. J. Am. Chem. Soc. 2016, 138, 628-634. [CrossRef]

207. Liu, B.; Wang, L.; Tao, H.; Xu, M.; Zou, J.; Ning, H.; Peng, J.; Cao, Y. Doping-Free Tandem White Organic Light-Emitting Diodes. Sci. Bull. 2017, 62, 1193-1200. [CrossRef]

208. Yoshihiro, O. Color rendering and luminous efficacy of white LED spectra. Proc. SPIE 2004, 88, 5530.

209. Lei, D.; Tang, X.; Xu, M.F.; Shi, X.B.; Wang, Z.K.; Liao, L.S. Lithium Hydride Doped Intermediate Connector for High-Efficiency and Long-Term Stable Tandem Organic Light-Emitting Diodes. ACS Appl. Mater. Interfaces 2014, 6, 18228-18232.

210. Sun, Q.J.; Wang, Y.A.; Li, L.S.; Wang, D.; Zhu, T.; Xu, J.; Yang, C.; Li, Y. Bright, Multicoloured Light-emitting Diodes Based on Quantum Dots. Nat. Photonics 2007, 1, 717-722. [CrossRef]

211. Qasim, K.; Wang, B.; Zhang, Y.; Li, P.; Wang, Y.; Li, S.; Lee, S.-T.; Liao, L.-S.; Lei, W.; Bao, Q. Solution-Processed Extremely Efficient Multicolor Perovskite Light-Emitting Diodes Utilizing Doped Electron Transport Layer. Adv. Funct. Mater. 2017, 27, 1606874. [CrossRef] 
212. Shi, Z.; Li, Y.; Zhang, Y.; Chen, Y.; Li, X.; Wu, D.; Xu, T.; Shan, C.; Du, G. High-efficiency and air-stable perovskite quantum dots light-emitting diodes with an all-inorganic heterostructure. Nano Lett. 2017, 17, 313-321. [CrossRef] [PubMed]

213. Shi, Z.; Li, S.; Li, Y.; Ji, H.; Li, X.; Wu, D.; Xu, T.; Chen, Y.; Tian, Y.; Zhang, Y. Strategy of Solution-Processed All-Inorganic Heterostructure for Humidity/Temperature Stable Perovskite Quantum Dot Light-Emitting Diodes. ACS Nano 2018, 12, 1462-1472. [CrossRef] [PubMed]

214. Liu, L.; Wang, Z.; Sun, W.; Zhang, J.; Hu, S.; Hayat, T.; Alsaedi, A.; Tan, Z. All-solution-processed perovskite light-emitting diodes with all metal oxide transport layers. Chem. Commun. 2018, 54, 13283-13286. [CrossRef] [PubMed]

215. Subramanian, A.; Pan, Z.; Zhang, Z.; Ahmad, I.; Chen, J.; Liu, M.; Cheng, S.; Xu, Y.; Wu, J.; Lei, W.; et al. Interfacial Energy-Level Alignment for High-Performance All-Inorganic Perovskite $\mathrm{CsPbBr}_{3}$ Quantum Dot-Based Inverted Light-Emitting Diodes. ACS Appl. Mater. Interfaces 2018, 10, 13236-13243. [CrossRef] [PubMed]

216. Khan, Q.; Subramanian, A.; Yu, G.; Maaz, K.; Li, D.; Sagar, R.U.R.; Chen, K.; Lei, W.; Shabbir, B.; Zhang, Y. Structure optimization of perovskite quantum dot light-emitting diodes. Nanoscale. 2019, 11, 5021-5029. [CrossRef] [PubMed]

217. Zhou, Y.; Fuentes-Hernandez, C.; Shim, J.; Meyer, J.; Giordano, A.J.; Li, H.; Winget, P.; Papadopoulos, T.; Cheun, H.; Kim, J.; et al. A universal method to produce low-work function electrodes for organic electronics. Science 2012, 336, 327-332. [CrossRef]

218. Gao, Z.; Zheng, Y.; Wang, Z.; Yu, J. Improving the stability and efficiency of perovskite light-emitting diodes via an insulating layer of polyethylenimine ethoxylated. J. Lumin. 2018, 201, 359-363. [CrossRef]

219. Wang, J.; Wang, N.; Jin, Y.; Si, J.; Tan, Z.-K.; Du, H.; Cheng, L.; Dai, X.; Bai, S.; He, H.; et al. Interfacial Control Toward Efficient and Low-Voltage Perovskite Light-Emitting Diodes. Adv. Mater. 2015, 27, 2311-2316. [CrossRef]

220. Luo, D.; Chen, Q.; Liu, B.; Qiu, Y. Emergence of Flexible White Organic Light-Emitting Diodes. Polymers 2019, 11, 384. [CrossRef]

221. Han, T.-H.; Lee, Y.; Choi, M.-R.; Woo, S.-H.; Bae, S.-H.; Hong, B.H.; Ahn, J.-H.; Lee, T.-W. Extremely efficient flexible organic light-emitting diodes with modified graphene anode. Nat. Photon. 2012, 6, 105-110. [CrossRef]

222. Ji, W.Y.; Zhao, J.L.; Sun, Z.C.; Xie, W.F. High-color-rendering flexible top-emitting warm-white organic light emitting diode with a transparent multilayer cathode. Org. Electron. 2011, 12, 1137-1141. [CrossRef]

223. Ji, W.Y.; Zhang, L.T.; Xu, K.; Xie, W.F.; Zhang, H.Z.; Liu, G.Q.; Yao, J.B. Semitransparent white organic light-emitting devices with symmetrical electrode structure. Org. Electron. 2011, 12, 2192-2197. [CrossRef]

224. Li, N.; Oida, S.; Tulevski, G.S.; Han, S.-J.; Hannon, J.B.; Sadana, D.K.; Chen, T.-C. Efficient and bright organic light-emitting diodes on single-layer graphene electrodes. Nat. Commun. 2013, 4, 2294. [CrossRef]

225. Liu, X.-K.; Zhan, C.; Jian, Q.; Wen-Jun, Z.; Bo, W.; Hoi Lam, T.; Zhu, F.; Zhang, X.-H.; Lee, C.-S. Organic light-emitting devices: Remanagement of singlet and triplet excitons in single-emissive-layer hybrid white organic light-emitting devices using thermally activated delayed fluorescent blue exciplex. Adv. Mater. 2015, 27, 7079-7085. [CrossRef]

226. Sun, N.; Wang, Q.; Zhao, Y.B.; Chen, Y.H.; Yang, D.Z.; Zhao, F.C.; Chen, J.S.; Ma, D.G. High-Performance Hybrid White Organic Light-Emitting Devices without Interlayer between Fluorescent and Phosphorescent Emissive Regions. Adv. Mater. 2014, 26, 1617-1621. [CrossRef]

227. Yook, K.S.; Jeon, S.O.; Joo, C.W.; Lee, J.Y. Color stability and suppressed efficiency roll-off in white organic light-emitting diodes through management of interlayer and host properties. J. Ind. Eng. Chem. 2009, 15, 420-422. [CrossRef]

228. Yang, X.; Ma, Y.; Mutlugun, E.; Zhao, Y.; Leck, K.S.; Tan, S.T.; Demir, H.V.; Zhang, Q.; Du, H.; Sun, X.W. Stable, Efficient, and All-Solution-Processed Quantum Dot Light-Emitting Diodes with Double-Sided Metal Oxide Nanoparticle Charge Transport Layers. ACS Appl. Mater. Interfaces 2014, 6, 495-499. [CrossRef]

229. Liu, B.; Wang, L.; Gu, H.; Sun, H.; Demir, H.V. Highly Efficient Green Light-Emitting Diodes from All-Inorganic Perovskite Nanocrystals Enabled by a New Electron Transport Layer. Adv. Opt. Mater. 2018, 5, 180022. [CrossRef] 
230. Liu, B.; Wang, L.; Xu, M.; Tao, H.; Gao, D.; Zou, J.; Lan, L.; Ning, H.; Peng, J.; Cao, Y. Extremely Stable-color Flexible White Organic Light-emitting Diodes with Efficiency Exceeding $100 \mathrm{~lm} \mathrm{~W}^{-1}$. J. Mater. Chem. C 2014, 2, 9836-9841. [CrossRef]

231. Kinner, L.; Nau, S.; Popovic, K.; Sax, S.; Burgués-Ceballos, I.; Hermerschmidt, F.; Lange, A.; Boeffel, C.; Choulis, S.A.; List-Kratochvil, E.J.W. Inkjet-printed embedded Ag-PEDOT: PSS electrodes with improved light out coupling effects for highly efficient ITO-free blue polymer light emitting diodes. Appl. Phys. Lett. 2017, 110, 101107. [CrossRef]

232. Su, S.-J.; Gonmori, E.; Sasabe, H.; Kido, J. Highly efficient organic blue- and white-light-emitting devices having a carrier- and exciton-confining structure for reduced efficiency roll-off. Adv. Mater. 2008, 20, 4189-4194. [CrossRef]

233. Zhang, M.; Wang, K.; Zheng, C.-J.; Liu, W.; Lin, H.; Tao, S.-L.; Zhang, X.-H. Efficient, color-stable and high color-rendering-index white organic light-emitting diodes employing full thermally activated delayed fluorescence system. Org. Electron. 2017, 50, 466-472. [CrossRef]

234. Nishide, J.-I.; Nakanotani, H.; Hiraga, Y.; Adachi, C. High-efficiency white organic light-emitting diodes using thermally activated delayed fluorescence. Appl. Phys. Lett. 2014, 104, 233304. [CrossRef]

235. Li, G.R.; Tan, Z.K.; Di, D.W.; Lai, M.L.; Jiang, L.; Lim, J.H.W.; Friend, R.H.; Greenham, N.C. Efficient light-emitting diodes based on nanocrystalline perovskite in a dielectric polymer matrix. Nano Lett. 2015, 15, 2640-2644. [CrossRef]

236. Li, J.Q.; Bade, S.G.R.; Shan, X.; Yu, Z.B. Single-Layer Light-Emitting Diodes Using Organometal Halide Perovskite/Poly (ethylene oxide) Composite Thin Films. Adv. Mater. 2015, 27, 5196-5202. [CrossRef]

237. Yu, J.C.; Kim, D.B.; Jung, E.D.; Lee, B.R.; Song, M.H. High-performance perovskite light-emitting diodes via morphological control of perovskite films. Nanoscale 2016, 8, 7036-7042. [CrossRef]

238. Wang, Z.B.; Cheng, T.; Wang, F.Z.; Dai, S.Y.; Tan, Z.A. Morphology Engineering for High-Performance and Multicolored Perovskite Light-Emitting Diodes with Simple Device Structures. Small 2016, 12, 4412-4420. [CrossRef]

239. Yuan, M.; Quan, L.N.; Comin, R.; Walters, G.; Sabatini, R.; Voznyy, O.; Hoogland, S.; Zhao, Y.; Beauregard, E.M.; Kanjanaboos, P.; et al. Perovskite energy funnels for efficient light-emitting diodes. Nat. Nanotechnol. 2016, 11, 872-877. [CrossRef]

240. Shi, Y.; Wu, W.; Dong, H.; Li, G.; Xi, K.; Divitini, G.; Ran, C.; Yuan, F.; Zhang, M.; Jiao, B.; et al. A Strategy for Architecture Design of Crystalline Perovskite Light-Emitting Diodes with High Performance. Adv. Mater. 2018, 30, 1800251. [CrossRef]

241. Yao, J.-S.; Ge, J.; Wang, K.-H.; Zhang, G.; Zhu, B.-S.; Chen, C.; Zhang, Q.; Luo, Y.; Yu, S.-H.; Yao, H.-B. Few-Nanometer-Sized $\alpha-\mathrm{CsPbI}_{3}$ Quantum Dots Enabled by Strontium Substitution and Iodide Passivation for Efficient Red-Light Emitting Diodes. J. Am. Chem. Soc. 2019, 141, 2069-2079. [CrossRef]

242. Zhou, L.; Xiang, H.-Y.; Shen, S.; Li, Y.-Q.; Chen, J.-D.; Xie, H.-J.; Goldthorpe, I.A.; Chen, L.-S.; Lee, S.-T.; Tang, J.-X. High-performance flexible organic light-emitting diodes using embedded silver network transparent electrodes. ACS Nano 2014, 8, 12796-12805. [CrossRef]

243. Zheng, X.; Hou, Y.; Sun, H.-T.; Mohammed, O.F.; Sargent, E.H.; Bakr, O.M. Reducing Defects in Halide Perovskite Nanocrystals for Light-Emitting Applications. J. Phys. Chem. Lett. 2019, 10, 2629-2640. [CrossRef]

244. Xu, L.-H.; Ou, Q.-D.; Li, Y.-Q.; Zhang, Y.-B.; Zhao, X.-D.; Xiang, H.-Y.; Chen, J.-D.; Zhou, L.; Lee, S.-T.; Tang, J.-X. Microcavity-Free Broadband Light Outcoupling Enhancement in Flexible Organic Light-Emitting Diodes with Nanostructured Transparent Metal-Dielectric Composite Electrodes. ACS Nano 2016, 10, 1625-1632. [CrossRef]

245. Koo, J.-R.; Lee, S.J.; Lee, H.W.; Lee, D.H.; Yang, H.J.; Kim, W.Y.; Kim, Y.K. Flexible bottom-emitting white organic light-emitting diodes with semitransparent Ni/Ag/Ni anode. Opt. Express 2013, 21, 11086-11094.

246. Chen, S.F.; Zhang, Q.; Shang, W.J.; Liu, L.H.; Yu, H.T.; Zhang, S.; Deng, L.L.; Wang, M.; Wang, M.H.; Li, X.; et al. Interfacial engineering of graphene for highly efficient blue and white organic light-emitting devices. Sci. Rep. 2018, 8, 8155. [CrossRef]

247. Preinfalk, J.B.; Eiselt, T.; Wehlus, T.; Rohnacher, V.; Hanemann, T.; Gomard, G.; Lemmer, U. Large-Area Screen-Printed Internal Extraction Layers for Organic Light-Emitting Diodes. ACS Photonics 2017, 4, 928-933. [CrossRef] 
248. Wu, C.; Wu, T.; Yan, Y.; Mcleod, J.A.; Wang, Y.; Zou, Y.; Zhai, T.; Li, J.; Ban, M.; Song, T.; et al. Alternative Type Two-Dimensional-Three-Dimensional Lead Halide Perovskite with Inorganic Sodium Ions as a Spacer for High-Performance Light-Emitting Diodes. ACS Nano. 2019, 13, 1645-1654. [CrossRef]

249. Lu, M.; Zhang, Y.; Wang, S.; Guo, J.; Yu, W.W.; Rogach, A.L. Metal Halide Perovskite Light-Emitting Devices: Promising Technology for Next-Generation Displays. Adv. Funct. Mater. 2019, 1902008. [CrossRef]

250. Yang, D.; Cao, M.; Zhong, Q.; Li, P.; Zhang, X.; Zhang, Q. All-inorganic cesium lead halide perovskite nanocrystals: Synthesis, surface engineering and applications. J. Mater. Chem. C 2019, 7, 757-789. [CrossRef]

251. Kim, B.S.; Yook, K.S.; Lee, J.Y. Above 20\% External Quantum Efficiency in Novel Hybrid White Organic Light-Emitting Diodes Having Green Thermally Activated Delayed Fluorescent Emitter. Sci. Rep. 2014, 4, 6019. [CrossRef] [PubMed]

252. Li, X.L.; Xie, G.Z.; Liu, M.; Chen, D.C.; Cai, X.Y.; Peng, J.B.; Cao, Y.; Su, S.J. High-Efficiency WOLEDs with High Color-Rendering Index based on a Chromaticity-Adjustable Yellow Thermally Activated Delayed Fluorescence Emitter. Adv. Mater. 2016, 28, 4614-4619. [CrossRef] [PubMed]

253. Wang, Q.; Ding, J.; Ma, D.; Cheng, Y.; Wang, L.; Jing, X.; Wang, F. Harvesting Excitons Via Two Parallel Channels for Efficient White Organic LEDs with Nearly 100\% Internal Quantum Efficiency: Fabrication and Emission-Mechanism Analysis. Adv. Funct. Mater. 2009, 19, 84-95. [CrossRef]

254. Khalfin, S.; Bekenstein, Y. Advances in Lead-Free Double Perovskite Nanocrystals, Engineering Band-gaps and Enhancing Stability Through Composition Tunabilty. Nanoscale. 2019, 11, 8665-8679. [CrossRef] [PubMed]

255. Yang, B.; Hong, F.; Chen, J.; Tang, Y.; Yang, L.; Xia, X.; Guo, J.; He, H.; Yang, S.; Deng, W.; et al. Colloidal Synthesis and Charge-Carrier Dynamics of $\mathrm{Cs}_{2} \mathrm{AgSb}_{1-y} \mathrm{Bi}_{y} \mathrm{X}_{6}(\mathrm{X}: \mathrm{Br}, \mathrm{Cl} ; 0 \leq y \leq 1)$ Double Perovskite Nanocrystals. Angew. Chem. Int. Edit. 2019, 58, 2278-2283. [CrossRef]

256. Fan, Q.; Biesold, M.; Gill, V.; Xu, Q.; Pan, S.; Peng, J.; Ma, J.; Lin, Z. Lead-Free Halide Perovskite Nanocrystals: Crystal Structures, Synthesis, Stabilities, and Optical Properties. Angew. Chem. Int. Edit. 2019. [CrossRef]

257. Chen, N.; Cai, T.; Li, W.; Hills-Kimball, K.; Yang, H.; Que, M.; Nagaoka, Y.; Liu, Z.; Yang, D.; Dong, A.; et al. Yb-and Mn-Doped Lead-Free Double-Perovskite $\mathrm{Cs}_{2} \mathrm{AgBiX}_{6}(\mathrm{X}=\mathrm{Cl}-, \mathrm{Br}-)$ Nanocrystals. ACS Appl. Mater. Interfaces 2019, 11, 16855-16863. [CrossRef]

258. Liu, Y.; Jing, Y.; Zhao, J.; Liu, Q.; Xia, Z. Design Optimization of Lead-Free Perovskite $\mathrm{Cs}_{2} \mathrm{AgInCl}_{6}$ : Bi Nanocrystals with 11.4\% Photoluminescence Quantum Yield. Chem. Mater. 2019, 31, 3333-3339. [CrossRef]

259. Sasabe, H.; Kido, J. Development of High Performance OLEDs for General Lighting. J. Mater. Chem. C 2013, 1, 1699-1707. [CrossRef]

260. Wang, Q.; Ma, D. Management of Charges and Excitons for High-performance White Organic Light-emitting Diodes. Chem. Soc. Rev. 2010, 39, 2387-2398. [CrossRef]

261. Jou, J.-H.; Kumar, S.; Agrawal, A.; Li, T.-H.; Sahoo, S. Approaches for Fabricating High Efficiency Organic Light Emitting Diodes. J. Mater. Chem. C 2015, 3, 2974-3002. [CrossRef]

262. Zou, S.; Liu, Y.; Li, J.; Liu, C.; Feng, R.; Jiang, F.; Li, Y.; Song, J.; Zeng, H.; Hong, M.; et al. Stabilizing Cesium Lead Halide Perovskite Lattice through Mn (II)-Substitution for Air-Stable Light-Emitting Diodes. J. Am. Chem. Soc. 2017, 139, 11443-11450. [CrossRef] [PubMed]

263. Ding, N.; Zhou, D.; Sun, X.; Xu, W.; Xu, H.; Pan, G.; Li, D.; Zhang, S. Highly stable and water-soluble monodisperse $\mathrm{CsPbX}_{3} / \mathrm{SiO}_{2}$ nanocomposites for white-LED and cells imaging. Nanotechnology 2018, 29, 345703. [CrossRef] [PubMed]

264. Zhu, Y.; He, Y.; Gong, J.; Feng, X.; Peng, H.; Wang, W.; He, H.; Liu, H.; Wang, L. Highly stable all-inorganic $\mathrm{CsPBr}_{3}$ nanocrystals film encapsulated with alumina by plasma-enhanced atomic layer deposition. Mater. Express 2018, 8, 469-474. [CrossRef]

265. Li, F.; Guo, C.; You, L.; Jin, X.; Deng, W.; Zhao, F.; Zhang, Q.; Huang, Y.; Li, Q. Photoinstable hybrid all-inorganic halide perovskite quantum dots as single downconverters for white light emitting devices. Org. Electron. 2018, 63, 318-327. [CrossRef]

266. Shi, Z.; Li, Y.; Li, S.; Li, X.; Wu, D.; Xu, T.; Tian, Y.; Chen, Y.; Zhang, Y.; Zhang, B.; et al. Localized Surface Plasmon Enhanced All-Inorganic Perovskite Quantum Dot Light-Emitting Diodes Based on Coaxial Core/Shell Heterojunction Architecture. Adv. Funct. Mater. 2018, 28, 1707031. [CrossRef]

267. Li, Q.-F.; Wang, J.-T.; Tian, B.; Kong, S.; Wang, T.; Wang, Z. Hybridization of CsPbBr 3 Perovskite Nanocrystals with Polymer Nanofiber to Improve their Luminescence Stability. Eur. J. Inorg. Chem. 2018, 4215-4220. [CrossRef] 
268. Chen, L.-C.; Tien, C.-H.; Tseng, Z.-L.; Dong, Y.-S.; Yang, S. Influence of PMMA on All-Inorganic Halide Perovskite $\mathrm{CsPbBr}_{3}$ Quantum Dots Combined with Polymer Matrix. Materials 2019, 12, 985. [CrossRef]

269. Dameron, A.A.; Davidson, S.D.; Burton, B.B.; Carcia, P.F.; Mclean, R.S.; George, S.M. Gas Diffusion Barriers on Polymers Using Multilayers Fabricated by $\mathrm{Al}_{2} \mathrm{O}_{3}$ and Rapid $\mathrm{SiO}_{2}$ Atomic Layer Deposition. J. Phys. Chem. C 2008, 112, 4573-4580. [CrossRef]

270. Seo, S.-W.; Jung, E.; Seo, S.J.; Chae, H.; Chung, H.K.; Cho, S.M. Toward fully flexible multilayer moisture-barriers for organic light-emitting diodes. J. Appl. Phys. 2013, 114, 143505. [CrossRef]

271. Park, J.-S.; Chae, H.; Chung, H.K.; Lee, S.I. Thin film encapsulation for flexible AM-OLED: A review. Semicond. Sci. Technol. 2011, 26, 034001. [CrossRef]

272. Wei, Z.; Xing, J. The Rise of Perovskite Light-Emitting Diodes. J. Phys. Chem. Lett. 2019, 10, 3035-3042. [CrossRef] [PubMed]

273. Le, Q.V.; Jang, H.W.; Kim, S.Y. Recent Advances toward High-Efficiency Halide Perovskite Light-Emitting Diodes: Review and Perspective. Small Methods 2018, 2, 1700419.

274. Zhao, X.; Ng, J.D.A.; Friend, R.H.; Tan, Z.-K. Opportunities and Challenges in Perovskite Light-Emitting Devices. ACS Photonics 2018, 5, 3866-3875. [CrossRef]

275. Xiao, P.; Huang, J.; Dong, T.; Xie, J.; Yuan, J.; Luo, D.; Liu, B. Room-temperature Fabricated Thin-Film Transistors Based on Compounds with Lanthanum and Main Family Element Boron. Molecules 2018, $23,1373$. [CrossRef] [PubMed]

276. Al-Asbahi, B.A.; Jumali, M.H.H.; AlSalhi, M.S. Enhanced Optoelectronic Properties of PFO/Fluorol 7GA Hybrid Light Emitting Diodes via Additions of $\mathrm{TiO}_{2}$ Nanoparticles. Polymers 2016, 8, 334. [CrossRef] [PubMed]

277. Zhang, L.; Xiao, W.; Wu, W.; Liu, B. Research Progress on Flexible Oxide-Based Thin Film Transistors. Appl. Sci. 2019, 9, 773. [CrossRef]

278. Ji, H.; Shi, Z.; Sun, X.; Li, Y.; Li, S.; Lei, L.; Wu, D.; Xu, T.; Li, X.; Du, G. Vapor-Assisted Solution Approach for High-Quality Perovskite $\mathrm{CH}_{3} \mathrm{NH}_{3} \mathrm{PbBr}_{3}$ Thin Films for High-Performance Green Light-Emitting Diode Applications. ACS Appl. Mater. Interfaces 2017, 9, 42893-42904. [CrossRef] [PubMed]

279. Fan, F.; Kanjanaboos, P.; Saravanapavanantham, M.; Beauregard, E.; Ingram, G.; Yassitepe, E.; Adachi, M.M.; Voznyy, O.; Johnston, A.K.; Walters, G.; et al. Colloidal CdSe1-X SXNanoplatelets with Narrow and Continuously-Tunable Electroluminescence. Nano Lett. 2015, 15, 4611-4615. [CrossRef]

280. Saraf, R.; Pu, L.; Maheshwari, V. A Light Harvesting, Self-Powered Monolith Tactile Sensor Based on Electric Field Induced Effects in $\mathrm{MAPbI}_{3}$ Perovskite. Adv. Mater. 2018, 30, 1705778. [CrossRef]

281. Weng, Z.; Qin, J.; Umar, A.A.; Wang, J.; Zhang, X.; Wang, H.; Cui, X.; Li, X.; Zheng, L.; Zhang, Y. Lead-Free Cs2BiAgBr6 Double Perovskite-Based Humidity Sensor with Superfast Recovery Time. Adv. Funct. Mater. 2019, 29, 1902234. [CrossRef]

282. Yang, X.; Ma, L.-F.; Yan, D. Facile Synthesis of 1D Organic-Inorganic Perovskite Micro-Belts with High Water Stability for Sensor and Photonic Applications. Chem. Sci. 2019, 10, 4567-4572. [CrossRef] [PubMed]

283. Li, Y.; Shi, Z.; Lei, L.; Ma, Z.; Zhang, F.; Li, S.; Wu, D.; Xu, T.; Li, X.; Shan, C.; et al. Controllable Vapor-Phase Growth of Inorganic Perovskite Microwire Networks for High-Efficiency and Temperature-Stable Photodetectors. ACS Photonics 2018, 5, 2524-2532. [CrossRef]

284. Gui, P.; Chen, Z.; Li, B.; Yao, F.; Zheng, X.; Lin, Q.; Fang, G. High-Performance Photodetectors Based on Single All-Inorganic CsPbBr 3 Perovskite Microwire. ACS Photonics 2018, 5, 2113-2119. [CrossRef]

285. Algadi, H.; Mahata, C.; Woo, J.; Lee, M.; Kim, M.; Lee, T. Enhanced Photoresponsivity of All-Inorganic $\left(\mathrm{CsPbr}_{3}\right)$ Perovskite Nanosheets Photodetector with Carbon Nanodots (CDs). Electronics 2019, 8, 678. [CrossRef]

(C) 2019 by the authors. Licensee MDPI, Basel, Switzerland. This article is an open access article distributed under the terms and conditions of the Creative Commons Attribution (CC BY) license (http://creativecommons.org/licenses/by/4.0/). 